\title{
Deeper Understanding of Interstitial Boron-Doped Anatase Thin Films as A Multifunctional Layer Through Theory and Experiment
}

Miguel Quesada-Gonzalez, ${ }^{\dagger}$ Benjamin A. D. Williamson, ${ }^{\dagger, \S}$ Carlos Sotelo-Vazquez, ${ }^{\dagger}$ Andreas Kafizas, ${ }^{\perp}$ Nicolas D. Boscher, ${ }^{\ddagger \odot}$ Raul Quesada-Cabrera, ${ }^{\dagger}$ David O. Scanlon, ${ }^{\dagger, \S, \| \odot ~ C l a i r e ~ J . ~ C a r m a l t, ~}{ }^{\dagger \odot}$ and Ivan P. Parkin ${ }^{*}{ }^{\dagger}$

${ }^{\dagger}$ Department of Chemistry, Christopher Ingold Building, University College London, 20 Gordon Street, London WC1H 0AJ, U.K.

${ }^{\ddagger}$ Department of Materials Research and Technology, Luxembourg Institute of Science and Technology, 5 Avenue des Hauts-Fourneaux, Esch-sur-Alzette, L-4362, Luxembourg

${ }^{\S}$ Thomas Young Centre, University College London, Gower Street, London WC1E 6BT, United Kingdom

"Diamond Light Source Ltd., Diamond House, Harwell Science and Innovation Campus, Didcot, Oxfordshire OX11 0DE, U.K.

${ }^{\perp}$ Department of Chemistry, Imperial College London, London SW7 2AZ, U.K.

Supporting Information

ABSTRACT: Thin films of interstitial boron-doped anatase $\mathrm{TiO}_{2}$, with varying $\mathrm{B}$ concentrations, were deposited via onestep atmospheric pressure chemical vapor deposition (APCVD) on float glass substrates. The doped films showed a remarkable morphology and enhanced photoactivity when compared to their undoped analogues. The $\mathrm{TiO}_{2}: \mathrm{B}$ films also presented enhanced conductivity and electron mobility as measured by a Hall effect probe as well as a high adherence to the substrate, stability and extended lifetime. The structure and composition of the different samples of $\mathrm{TiO}_{2}: \mathrm{B}$ films were studied by X-ray diffraction (XRD), Raman spectroscopy, scanning electron microscopy (SEM), and dynamic secondary

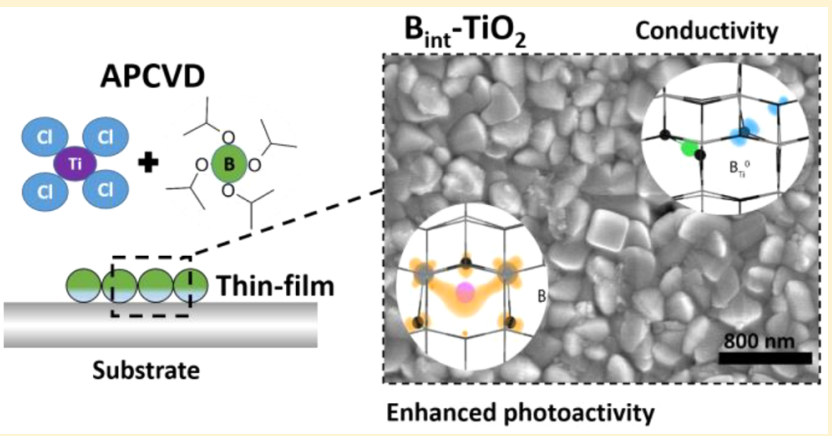
ion mass spectrometry (D-SIMS). Hybrid density functional theory was used to explore the defect chemistry of B-doped anatase and to understand the experimental results.

\section{INTRODUCTION}

Among all known photocatalytic materials, titanium dioxide $\left(\mathrm{TiO}_{2}\right)$ has been the most extensively studied photocatalytic material due to its multifunctional applications from desirable properties. ${ }^{1}$ There has been a large research drive into the degradation of organic pollutants leading to the industrial use of $\mathrm{TiO}_{2}$ for the production of environmental, self-cleaning and photocatalytic technologies such as the Pilkington Activ glass. In the last few decades, strenuous efforts have been made combining theory and experiment to fully understand the mechanisms of photocatalysis in $\mathrm{TiO}_{2}$ polymorphs. ${ }^{2,3}$

$\mathrm{TiO}_{2}$ has been synthesized using a wide range of synthetic methods, including sol-gel, ${ }^{4}$ hydrothermal, ${ }^{5}$ and electrochemical deposition, ${ }^{6}$ as well as physical $^{7}$ and chemical ${ }^{8,9}$ vapor deposition techniques. It is worth mentioning that the use of chemical vapor deposition methods to synthesize $\mathrm{TiO}_{2}$ materials presents advantages over other methodologies, such as removing the need for a calcination/annealing step which can drastically affect the nature and content of the dopant, ${ }^{10}$ and ease of industrial scale up.

$\mathrm{TiO}_{2}$, however, presents some disadvantages such as low conductivity and poor electron mobility which limits its usage for optoelectronic devices such as transparent conductive oxides (TCO). ${ }^{11,12}$ Even when donor doped with $\mathrm{Nb}$ or $\mathrm{W}$, resistivities fail to reach those of doped $\mathrm{SnO}_{2}, \mathrm{In}_{2} \mathrm{O}_{3}, \mathrm{ZnO}$ or $\mathrm{BaSnO}_{3}$. Anatase $\mathrm{TiO}_{2}$ possesses a wide band gap $\left(E_{\mathrm{g}} \sim 3.2\right.$ $\mathrm{eV}$ ) making it a UV absorber, limiting its efficiency as a photocatalytic material. To improve upon this and modify the morphology of $\mathrm{TiO}_{2}$, acceptor doping with a nonmetal or a transition metal has become one of the most widely studied areas of research in photocatalysis and materials science. ${ }^{13}$

Generally, upon acceptor doping, such as with nitrogen, the $\mathrm{N} 2 \mathrm{p}$ states sit slightly higher than the $\mathrm{O} 2 \mathrm{p}$ states at the valence band maximum (VBM) reducing the band gap and improving the efficiency of visible light absorption. However, when donor doped, the conductivity increases but usually at the expense of the photocatalytic activity. The majority of research on this has been in acceptor doping with nonmetals such as $\mathrm{N}, \mathrm{C}$, or B. ${ }^{14}$

Boron doping of $\mathrm{TiO}_{2}$ has attracted attention due to its enhanced photocatalytic activity under visible light. ${ }^{15}$ When boron is doped into the $\mathrm{TiO}_{2}$ lattice it can occupy both

Received: November 10, 2017

Revised: December 14, 2017

Published: December 15, 2017 
substitutional oxygen and titanium sites $\left(\mathrm{B}_{\mathrm{O}}\right.$ and $\mathrm{B}_{\mathrm{Ti}}$ respectively) as well as interstitially $\left(B_{i}\right)$ making it an amphoteric dopant. Experimentally a blue shift is observed in the band edge of $\mathrm{TiO}_{2}: \mathrm{B}$ when boron occupies an interstitial site indicative of a Mossec-Burstein shift. ${ }^{16}$ In addition, studies showing a red shift in the absorption edge are suggestive of substitutional B. This has been postulated as the creation of midgap states acting as absorption centers enhancing the visible light absorption and photocatalytic activity. ${ }^{17}$ It has been suggested in the literature that interstitial boron reduces $\mathrm{Ti}^{4+}$ to $\mathrm{Ti}^{3+}$ promoting the separation of the photoexcited electron and hole pairs suppressing their recombination and enhancing the photocatalytic activity. ${ }^{16}$ It should be noted, however, that excess electrons in anatase $\mathrm{TiO}_{2}$ are generally delocalized in the bulk but can localize on the surface. ${ }^{12}$

Previous synthesis of $\mathrm{TiO}_{2}: \mathrm{B}$ has been focused on the formation of powders by sol-gel, annealing, and hydrothermal methods. ${ }^{15}$ Recently, $\mathrm{TiO}_{2}$ : $\mathrm{B}$ thin films deposited by APCVD were reported for the first time by Carmichael et al. ${ }^{18}$ Analysis of the films showed substitutional boron which lead to remarkable rates of hydrogen production $\left(24 \mu \mathrm{L} \mathrm{cm}^{-2} \mathrm{~h}^{-1}\right)$ and more favorable photocurrent profiles when compared to undoped samples. Other APCVD routes have created interstitial B-doped $\mathrm{TiO}_{2}$ with the noticeable effect of interstitial boron in the surface morphology of the thin films. ${ }^{19}$ The films showed higher rates of photoactivity together with higher stability when compared to substitutional borondoped $\mathrm{TiO}_{2}$ films. Here, we present and report the study of the synthesis and characterization of a series of interstitial $\mathrm{TiO}_{2}: \mathrm{B}$ thin films, synthesized by one-step APCVD, containing different concentrations of boron. The impact which interstitial boron has on the morphology, structure and functional properties of such films is shown experimentally and by state-of-the-art $a b$ initio theoretical methods.

\section{EXPERIMENTAL METHODOLOGY}

The chemicals were purchased from Sigma-Aldrich and Acros Organics. Titanium tetrachloride $\left(\mathrm{TiCl}_{4}, 99.9 \%\right)$, ethyl acetate $\left(\mathrm{C}_{4} \mathrm{H}_{8} \mathrm{O}_{2}, 99.8 \%\right)$, and triisopropyl borate $\left(\mathrm{C}_{9} \mathrm{H}_{21} \mathrm{BO}_{3}, 98 \%\right)$ were used as titanium, oxygen, and boron sources, respectively. Octadecanoic (stearic) acid $\left(\mathrm{CH}_{3}\left(\mathrm{CH}_{2}\right)_{16} \mathrm{CHO}_{2}, 98.5 \%\right)$ was used to perform the photocatalytic assay.

2.1. Atmospheric Pressure Chemical Vapor Deposition (APCVD). The boron-doped $\mathrm{TiO}_{2}$ thin films were synthesized in a custom-built cold-walled CVD reactor at atmospheric pressure. ${ }^{20}$ The reactor consisted of a graphite block (320 mm long $\times 150 \mathrm{~mm}$ width) contained within a quartz glass tube. The graphite block contained three embedded Whatman heater cartridges and the temperature was controlled using $\mathrm{Pt}-\mathrm{Rh}$ thermocouples. Nitrogen gas (supplied by BOC) was used as the carrier gas to lead the precursor vapors into the reactor. The gas mixture was introduced through a triple manifold in order to ensure a laminar flow into the reactor. The carrier gas was preheated at $473 \mathrm{~K}$ and all the pipes of the CVD system were kept at that temperature. The precursors were heated independently in stainless steel bubblers in order to maintain their intended vapor pressures and ensure flow rate control. Before entering the CVD reactor, the precursors were quickly mixed in stainless steel mixing chambers at $523 \mathrm{~K}$, under controlled flow rate conditions.

The films were deposited at $773 \mathrm{~K}$ on float glass substrates $(89 \times 225 \times 4 \mathrm{~mm})$ supplied by the Pilkington NSG Group, precoated with a $\mathrm{SiO}_{2}$ barrier layer to prevent ion diffusion from the glass into the film. The glass substrates were cleaned using distilled water, acetone (99\%) and isopropanol (99.9\%) and dried in air prior to use. In a typical deposition, the temperature and mass flow rates were constant for metal $\left(\mathrm{TiCl}_{4}\right)$ and oxygen $\left(\mathrm{CH}_{3} \mathrm{COOC}_{2} \mathrm{H}_{5}\right)$ precursors as 340 and $310 \mathrm{~K}$ and $6.4 \times 10^{-3}$ and $3.04 \times 10^{-3} \mathrm{~g} \bullet \mathrm{min}^{-1}$, respectively. A range of boron-doped $\mathrm{TiO}_{2}$ films $\left(\mathrm{TiO}_{2}: \mathrm{B}\right)$ were synthesized using increasing mass flow rates of triisopropyl borate $\left(\mathrm{C}_{9} \mathrm{H}_{21} \mathrm{BO}_{3}\right)$ as boron precursor, namely $0.19 \times 10^{-3} \mathrm{~g}$. $\mathrm{min}^{-1}$ (sample A) $0.56 \times 10^{-3} \mathrm{~g} \cdot \mathrm{min}^{-1}$ (sample B) and $0.65 \times$ $10^{-3} \mathrm{~g} \cdot \mathrm{min}^{-1}$ (sample C).

2.2. Analytical Methods. X-ray diffraction (XRD) patterns of the films were obtained using a Lynxeye XE Bruker-Axs D8 diffractometer. The instrument operates with a $\mathrm{Cu}$ X-ray source, monochromated (K $\alpha 1,1.5406 \AA$ A). Films were analyzed with a glancing incident angle $(\theta)$ of $1^{\circ}$. Structural analysis of the powdery deposition was done by Powder XRD using a Bruker D4 Bragg-Brentano $\theta-2 \theta$ reflection geometry machine equipped with a $\mathrm{Cu} \mathrm{K} \alpha_{1+2}$ source powered at $40 \mathrm{kV}, 30 \mathrm{~mA}$ coupled with a postsample graphite monochromator and scintillation counter detector. The Joint Committee on Powder Diffraction Standards (JCPDS) was used to determine the crystal structure adopted. The lattice parameters and average crystal size was determined using a Le Bail model using the GSAS-EXPGUI software suite. ${ }^{21}$ Raman spectroscopy was carried out using a Renishaw 1000 spectrometer equipped with a $514 \mathrm{~nm}$ laser. The Raman system was calibrated using a silicon reference.

Characterization of the chemical profile of the thin films was carried out by dynamic secondary ion mass spectrometry (DSIMS) in a Cameca SC-Ultra instrument in positive ion mode, by a bombardment with $\mathrm{Cs}^{+}$ions, having an impact energy of $1.0 \mathrm{keV}$.

X-ray photoelectron spectroscopy (XPS) was used to determine the composition of the films and spectra were recorded on a Kratos Axis Nova spectrometer equipped with a monochromated $\mathrm{Al} \mathrm{K} \alpha \mathrm{X}$-ray source and delay line detector. Survey spectra were recorded with energy of $160 \mathrm{eV}$ and higher resolution spectra were recorded at $80 \mathrm{eV}$. A Filmetrics F20 single spot thin film machine was used to analyze film thicknesses. UV/visible spectroscopy was performed using a double monochromated PerkinElmer Lambda $950 \mathrm{UV} /$ vis/ NIR spectrophotometer in the 300-2500 $\mathrm{nm}$ range. Reflectance spectra were recorded for different positions in the range $300-2500 \mathrm{~nm}$ on a Helios double beam instrument standardized relative to a silicon mirror, which allowed the thickness of the films to be also be determined via the Swanepoel method. ${ }^{22}$ The morphology of the films was studied by Scanning Electron Microscopy (SEM). The images were taken using JEOL $6301(5 \mathrm{kV})$ and a JEOL JSM-6700F field.

The probe measurements (Hall effect) were conducted at room temperature on an Ecopia HMS-3000 device in the Van der Pauw configuration. ${ }^{27}$ Measurements were acquired at 0.58 $\mathrm{T}$ and a variable current of $0.1 \mu \mathrm{A}$ to $1 \mathrm{nA}$ on square-cut samples $(\approx 1 \times 1 \mathrm{~cm})$. Silver paint (Agar Scientific) was used to form ohmic contacts, the integrity of which were tested prior to measurement.

2.3. Photocatalytic Test. The photocatalytic activity of the films was evaluated during photodegradation of octadecanoic (stearic) acid. A thin layer of stearic acid was applied on the surface of the samples by dip-coating from a stearic acid solution $(0.05 \mathrm{M})$ in chloroform under UVA illumination 
(BLB Vilber-Lourmat, $2 \times 8 \mathrm{~W}, 365 \mathrm{~nm}, 2 \mathrm{~mW} \mathrm{~cm}{ }^{-2}$ ). A PerkinElmer RX-I Fourier transform infrared (FTIR) spectrometer was used to monitor,the disappearance of characteristic $\mathrm{C}-\mathrm{H}$ modes of the acid $\left(2958,2923\right.$, and $\left.2853 \mathrm{~cm}^{-1}\right)$. The photocatalytic rates were estimated from linear regression of the initial steps $(30-40 \%)$ of the curve of the integrated area vs illumination time. This estimation considered that 1 $\mathrm{cm}^{-1} \equiv 9.7 \times 10^{+15}$ molecules. ${ }^{23}$

\section{THEORETICAL METHODOLOGY}

Computational analysis using $a b$ initio methods has been carried out on the intrinsic defects and boron incorporation in anatase $\mathrm{TiO}_{2}$. These calculations have been carried out using the Vienna $a b$ initio simulation package, VASP, ${ }^{24-27}$ a periodic boundary, plane-wave density functional theory (DFT) code. The projector-augmented wave method (PAW) ${ }^{28}$ was employed to describe the interactions between the core electrons and the valence electrons of each species ( $\mathrm{Ti}:[\mathrm{Ar}]$, $\mathrm{O}:[\mathrm{He}]$ and $\mathrm{B}:[\mathrm{He}])$.

In this study the hybrid DFT functional, HSE06 (HeydScuzeria-Ernzerhof) ${ }^{29,30}$ was used to obtain accurate electronic and geometric results of $\mathrm{B}$-doped $\mathrm{TiO}_{2}$. Hybrid functionals are less inhibited by the short falls of standard DFT functionals which fail to describe the self-interaction error and thus underestimate band gaps resulting in an inaccurate picture of the defect chemistry of a system. Hybrid functionals have consistently displayed increased accuracy over standard DFT functionals in describing both the geometry and electronic structure for a range of semiconductors and insulators, ${ }^{12,31-41}$ and HSE06 has been shown to provide a good description of all polymorphs of $\mathrm{TiO}_{2} \cdot{ }^{12,42-48}$

A geometry optimization was carried out on the primitive cell of anatase $\mathrm{TiO}_{2}$ allowing the lattice vectors and angles, volume, and atoms to relax until the forces on all the atoms were less than $0.01 \mathrm{eV}$ atom $^{-1}$. In order to achieve an accurate convergence of the total energy and electronic structure, a 700 $\mathrm{eV}$ plane wave energy cutoff and a $\Gamma$-centered $7 \times 7 \times 5 k$ point lattice were used.

All the defect states calculated herein were simulated using a $3 \times 3 \times 1$ supercell containing 108 atoms using a $\Gamma$-centered $k$ point mesh of $2 \times 2 \times 2$ combined with a plane wave cutoff of $450 \mathrm{eV}$. Only the ions within the supercells were allowed to relax with the lattice vectors and angles kept fixed. All the defect calculations were spin-polarized, and the systems were deemed to be converged when the forces on all the atoms were less than $0.01 \mathrm{eV}$ atom $^{-1}$. The limiting phases were calculated using plane-wave energy cutoffs of $700 \mathrm{eV}$ and $\Gamma$-centered $k$ point meshes of $6 \times 6 \times 3$ and $8 \times 8 \times 8$ for $\mathrm{B}_{2} \mathrm{O}_{3}$ and $\mathrm{Ti}_{2} \mathrm{O}_{3}$ respectively.

3.1. Defect Formalism. The formation energy of a defect in charge state ' $\mathrm{q}$ ' is defined as

$$
\begin{aligned}
\Delta H_{\mathrm{f}}(D, q)= & \left(E^{\mathrm{D}, \mathrm{q}}-E^{\mathrm{H}}\right) \pm \sum_{i} n_{i} E\left(E_{i}+\mu_{i}\right) \\
& +q\left(E_{\mathrm{Fermi}}+\varepsilon_{\mathrm{VBM}}^{\mathrm{H}}+\Delta E_{\mathrm{pot}}\right)+q^{2} E_{\text {corr }}^{\mathrm{IC}} \\
& +E_{\text {corr }}^{\mathrm{BF}}
\end{aligned}
$$

$E^{D, q}$ and $E^{\mathrm{H}}$ refer to total energies of the defective cell in charge state " $q$ " and the host cell, respectively. $E_{\mathrm{i}}$ refers to the elemental reference energy (where " $i$ " is $\mathrm{Ti}_{(\mathrm{s})}, \mathrm{O}_{2(\mathrm{~g})}$ or $\mathrm{B}_{(\mathrm{s})}$ ) and $\mu_{\mathrm{i}}$ is the associated chemical potential. $n$ refers to the number of electrons taken away from or added to the external reservoir.
In this work the Fermi level $\left(E_{\text {Fermi }}\right)$ ranges from the valence band maximum (VBM) $(0 \mathrm{eV})$ to $\sim 1.7 \mathrm{eV}$ above the conduction band minimum (CBM). $\varepsilon_{V B M}^{H}$ refers to the eigenvalue of the $\mathrm{VBM}$ in the host material and $\Delta E_{\text {pot }}$ corresponds to the correction that is applied to account for the difference between the potential of the host and the defective supercells. Two more corrections are applied to account for the finite size effects of the supercell; the first is an image charge correction $E_{\text {corr }}^{I C}$ which corrects for the interaction of the charged defect and its own periodic images due to the long ranged nature of the Coulomb interaction. ${ }^{49,50}$ The image charge correction implemented herein uses the scheme formalized by Hine and Murphy, ${ }^{51}$ which utilizes the dielectric tensor. Lastly there is a band filling correction $\left(E_{\text {corr }}^{B F}\right)$ by Lany and Zunger, ${ }^{52,53}$ which is applied to shallow defects to account for the high defect concentrations present in supercell calculations.

3.2. Chemical Potential Limits. The chemical potentials in eq $1\left(\mu_{i}\right)$ can reflect the equilibrium growth conditions which can then be varied to simulate the experimental partial pressures defining the extremes of $n$-type and $p$-type defect formation. Under equilibrium conditions the chemical potentials are relative to the formation enthalpy of anatase:

$$
\mu_{\mathrm{Ti}}+2 \mu_{\mathrm{O}}=\Delta H_{\mathrm{f}}^{\mathrm{TiO}_{2}}=-9.14 \mathrm{eV}
$$

Because of the requirement that $\mathrm{TiO}_{2}$ is to be thermodynamically stable toward $\mathrm{Ti}_{2} \mathrm{O}_{3}$, a further restraint is imposed on the chemical potentials making the Ti-rich/O-poor boundary limited by

$$
2 \mu_{\mathrm{Ti}}+3 \mu_{\mathrm{O}}=\Delta H_{\mathrm{f}}^{\mathrm{Ti}_{2} \mathrm{O}_{3}}=-14.76 \mathrm{eV}
$$

These results correlate well with room-temperature experimental values $\left(-9.73\right.$ and $-15.76 \mathrm{eV}$ for $\mathrm{TiO}_{2}$ and $\mathrm{Ti}_{2} \mathrm{O}_{3}$, respectively ${ }^{54}$ ).

This results in the "extreme" set of growth conditions $T i$ rich/O-poor ( $n$-type favorable) where the chemical potentials are limited by the formation of $\mathrm{Ti}_{2} \mathrm{O}_{3}$ :

$$
\mu_{\mathrm{Ti}}=-2.11 \mathrm{eV} ; \mu_{\mathrm{O}}=-3.51 \mathrm{eV}
$$

And for Ti-poor/O-rich ( $p$-type favorable) conditions where the chemical potentials are limited by the formation of $\mathrm{O}_{2(\mathrm{~g})}$ :

$$
\mu_{\mathrm{Ti}}=-9.14 \mathrm{eV} ; \mu_{\mathrm{O}}=0 \mathrm{eV}
$$

To determine the solubility of the boron species, a limitation via the formation of a secondary phase, $\mathrm{B}_{2} \mathrm{O}_{3}$ is applied and is calculated tobe

$$
2 \mu_{\mathrm{B}}+3 \mu_{\mathrm{O}}=\Delta H_{\mathrm{f}}^{\mathrm{B}_{2} \mathrm{O}_{3}}=-13.09 \mathrm{eV}
$$

(The experimental formation energy at room temperature is determined to be $-13.20 \mathrm{eV}^{54}$ )

Therefore, under Ti-poor/O-rich and Ti-rich/O-poor conditions, $\mu_{B}=-6.55 \mathrm{eV}$ and $\mu_{B}=-1.27 \mathrm{eV}$, respectively.

The thermodynamic transition levels are displayed below (Figure 8) and show the evolution of a defect from charge state $q$ to $q^{\prime}$ at a certain Fermi level position calculated by

$$
\varepsilon_{\mathrm{D}} \frac{q}{q^{\prime}}=\frac{\Delta H_{\mathrm{f}}(D, q)-\Delta H_{\mathrm{f}}\left(D, q^{\prime}\right)}{q^{\prime}-q}
$$

Experimentally these transition levels can be seen by such techniques as deep level transient spectroscopy (DLTS). 
Table 1. Cell Parameters, Unit Cell Volume (V), Crystallite Size $(\tau)$, and Boron Content (in at. \%) of the Undoped and TiO ${ }_{2}: B$ Thin Films ${ }^{a}$

\begin{tabular}{|c|c|c|c|c|c|c|c|}
\hline sample & phase & $a[\AA]$ & $b[\AA]$ & $c[\AA]$ & $V\left[\AA^{3}\right]$ & $\tau(\mathrm{nm})$ & [B] (at. \%) \\
\hline \multirow[t]{2}{*}{ standards } & anatase & $3.7848(3)$ & $3.7848(3)$ & $9.5124(2)$ & 136.26 & - & N/A \\
\hline & rutile & $4.5941(1)$ & $4.5941(1)$ & $2.9589(1)$ & 62.45 & - & \\
\hline undoped & anatase & $3.7885(4)$ & $3.7885(4)$ & $9.5205(4)$ & 136.13 & 44.63 & 0 \\
\hline $\mathrm{TiO}_{2}: \mathrm{B}(\mathrm{A})$ & anatase & $3.7832(1)$ & $3.7832(1)$ & $9.5322(7)$ & 137.65 & 87.43 & $0.8-1.0$ \\
\hline $\mathrm{TiO}_{2}: \mathrm{B}(\mathrm{B})$ & anatase & $3.7811(8)$ & $3.7811(8)$ & $9.5087(2)$ & 135.94 & 79.51 & $2.0-3.0$ \\
\hline \multirow[t]{2}{*}{$\mathrm{TiO}_{2}: \mathrm{B}(\mathrm{C})$} & anatase & $3.8003(4)$ & $3.8003(4)$ & $9.5361(6)$ & 137.72 & 50.26 & $4.0-5.0$ \\
\hline & rutile & $4.5298(9)$ & $4.5298(9)$ & $2.9598(5)$ & 60.73 & 31.21 & \\
\hline
\end{tabular}

\section{RESULTS AND DISCUSSION}

A series of $\mathrm{B}$-doped $\mathrm{TiO}_{2}$ thin films, henceforth samples $\mathrm{A}, \mathrm{B}$, and $\mathrm{C}$, were produced by APCVD containing various boron concentrations, as indicated in Table 1 . The concentration of boron in the films were increased by varying the temperature of the bubbler and the mass flow rate. All the films were strongly adherent and passed the Scotch tape test, except for those using high flow rates of the boron precursor (e.g., sample C), which showed powdery areas across the glass substrate (Figure S2). The powder was easily removed using water or acetone. The formation of this powdery areas will be discussed below (vide infra).

4.1. Boron Doping. The presence of boron in the films and its oxidation state was elucidated using XPS and D-SIMS (Figure 1 and Figure S2). The Ti 2p peaks, located at binding energies of 458.9 and $464.6 \mathrm{eV}$ were identified as $\mathrm{Ti}-\mathrm{O}$ bonds

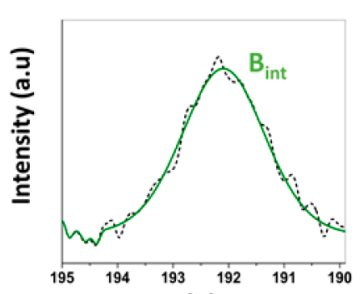

(a)

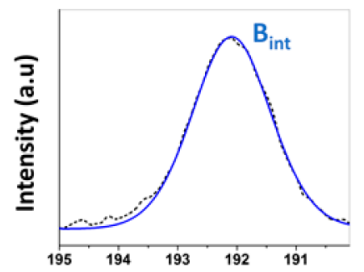

(b)

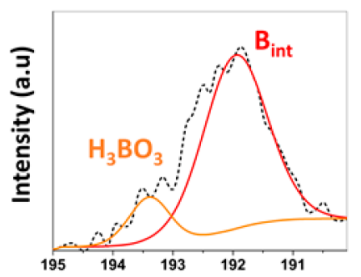

(c)

Binding energy (eV)

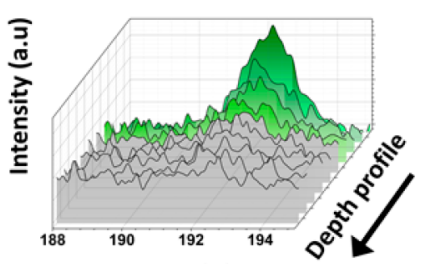

(d)

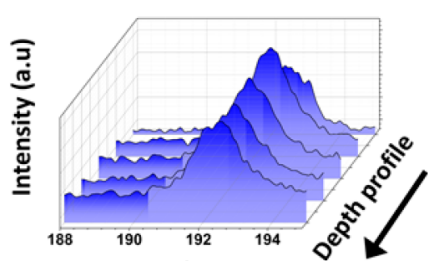

(e)

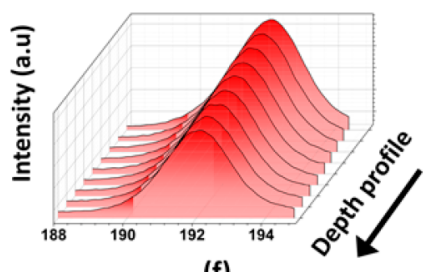

(f)

Binding energy (eV)
Figure 1. B 1s XPS surface and in depth profile spectra of $\mathrm{TiO}_{2}: \mathrm{B}$ samples: (a) $\mathrm{TiO}_{2}: \mathrm{B}(\mathrm{A})$; (b) $\mathrm{TiO}_{2}: \mathrm{B}(\mathrm{B})$ and (c) $\mathrm{TiO}_{2}: \mathrm{B}(\mathrm{C})$; (d-f) depth profiling spectrum of $\mathrm{TiO}_{2}: \mathrm{B}(\mathrm{A}), \mathrm{TiO}_{2}: \mathrm{B}(\mathrm{B})$, and $\mathrm{TiO}_{2}: \mathrm{B}(\mathrm{C})$ thin films, respectively. Dashed black lines in parts $a, b$, and $c$ represent the raw data (CPS) in XPS. of $\mathrm{Ti}^{4+}$ in $\mathrm{TiO}_{2}$ (Figure $\mathrm{S} 3 \mathrm{a}$ ). ${ }^{20}$ No other $\mathrm{Ti}^{4+}$ environment or reduced $\mathrm{Ti}^{3+}$ species were detected.

The $\mathrm{O} 1 \mathrm{~s}$ peak, located at $530.4 \mathrm{eV}$, is also consistent with the formation of $\mathrm{TiO}_{2}$. The total boron concentration of the $\mathrm{TiO}_{2}$ :B films was found to be in the range of $1-5$ at. \% (Table 1). Many discrepancies can be found in the literature with regards of the chemical environment of boron in boron-doped $\mathrm{TiO}_{2}$ materials. Generally, B 1s peaks at $190-191 \mathrm{eV}$ are attributed to substitutional boron in an oxygen position $\left(\mathrm{B}_{\mathrm{O}}\right)$ and peaks in the range 191-192 eV correspond to interstitial boron $\left(\mathrm{B}_{\mathrm{i}}\right){ }^{55}$ Boron can also be found in various other forms, including cationic $\mathrm{B}^{3+}$ in $\mathrm{B}_{2} \mathrm{O}_{3}$ and anionic $\mathrm{B}^{2-}$ in $\mathrm{TiB}_{2}$, with characteristic $B 1 s$ peaks at 193.1 and $187.5 \mathrm{eV}$, respectively. ${ }^{15,55}$ Our XPS results confirmed the presence of interstitial $B_{i}$ alone in most samples, with peaks within the range of $191.5-192 \mathrm{eV}$ in the $\mathrm{B} 1$ s environment. High flow rates of the boron precursor induced formation of boric acid, as identified by an additional peak at $193.5 \mathrm{eV}$ (Figure 1c). ${ }^{19}$ This peak, however, was only observed from surface analysis in sample C, not in the bulk of the sample (Figure 1f). The concentrations of boron in the bulk of the samples ranged between 0.8 and $1,2-3$ and $4-5$ at. \% for samples A, B, and C, as indicated in Table 1. Further analysis was carried out using D-SIMS (Figure $S 3 b-d$ ). It could be seen that, while the content of titanium and oxygen remained constant, the content of boron varied within the bulk of the films. In the case of samples A and B, boron is found mostly through the bulk of the film, as seen by D-SIMS depth profiling (Figure S3, parts b and c), whereas, in the case of sample $\mathrm{C}$, boron is found mostly on the surface of the thin film through at least $\sim 10 \mathrm{~nm}$, as XPS depth profiling analysis revealed (Figure 1f).

4.2. Structure Discussion. X-ray diffraction (XRD) and Raman spectroscopy were used to study the crystal structure of $\mathrm{TiO}_{2}$ present in the $\mathrm{TiO}_{2}: \mathrm{B}$ thin films. Figure 2 shows XRD patterns of $\mathrm{TiO}_{2}: \mathrm{B}$ samples alongside an undoped $\mathrm{TiO}_{2}$ thin film. The lattice parameters were determined using a Le Bail model, tooled with GSAS and compared with literature powder standards of anatase and rutile $\mathrm{TiO}_{2}{ }^{56}$ All samples confirmed the presence of anatase $\mathrm{TiO}_{2}$ only, except for sample $\mathrm{C}$ that showed traces of the rutile phase, as evidenced by an additional peak at $2 \theta=27.7^{\circ}$ (Figure $2 \mathrm{~d}$ ). The proportion of rutile phase in sample $\mathrm{C}$, calculated from the XRD data, was estimated around a relative value of $\sim 15 \%$ of the total. The presence of rutile at relatively low temperature-the typical anatase-rutile transformation temperature is above $700{ }^{\circ} \mathrm{C}$-can be explained from changes in the $\mathrm{pH}$ of the precursors mixture in the gas phase, which may induce changes in the nucleation rates of the $\mathrm{TiO}_{2}$ nanoparticles. As previously reported by Sabyrov et al., ${ }^{57}$ the generation of smaller initial nanoparticles of anatase $\mathrm{TiO}_{2}$ in acidic conditions and at high temperatures 


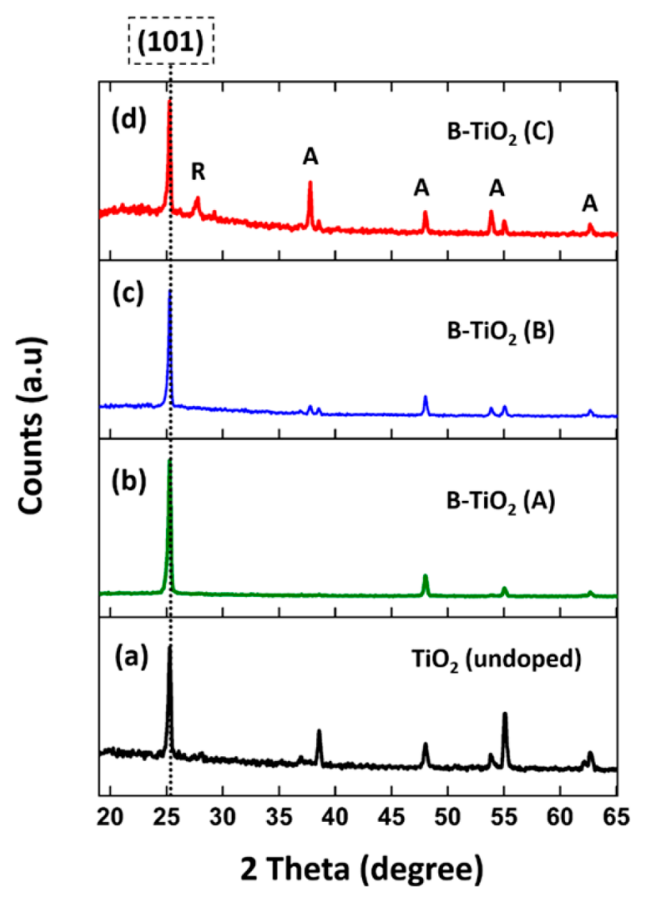

Figure 2. XRD patterns of undoped and B-doped $\mathrm{TiO}_{2}$ thin films (A $=$ anatase and $\mathrm{R}=$ rutile); (a) undoped $\mathrm{TiO}_{2}$; (b) sample $\mathrm{TiO}_{2}: \mathrm{B}(\mathrm{A})$; (c) sample $\mathrm{TiO}_{2}: \mathrm{B}(\mathrm{B}) ;$ (d) sample $\mathrm{TiO}_{2}: \mathrm{B}$ (C). Dotted line represents the crystalline plane (101) of anatase.

increased and induced the phase transformation rate of rutile $\mathrm{TiO}_{2}$. Pore et al. ${ }^{58}$ reported a similar effect for the synthesis of S-doped $\mathrm{TiO}_{2}$ films using atomic layer deposition (ALD).

Extracted from Le Bail refinement, the average crystallite size of the doped samples increased compared to undoped $\mathrm{TiO}_{2}$ (Table 1) but decreased upon apparently increasing levels of boron in the structure. A potential explanation for this is a concurrent formation of a boron-containing byproduct upon increasing flow rates of the boron precursor. This is plausible considering that the B 1s XPS peaks in the bulk were weak and broad (Figure 1d, 1e and 1f) and thus the levels of doped boron in the $\mathrm{TiO}_{2}$ structure may be overestimated. The mentioned byproduct could be boric acid $\left(\mathrm{H}_{3} \mathrm{BO}_{3}\right)$, as inferred from the XPS results from sample $\mathrm{C}$ (Figure 1c). The formation of boric acid (or sassolite) was indeed confirmed by
$\mathrm{XRD}$ analysis of the powdery sections in this sample (Figure S2).

XRD also suggested the addition of the boron dopant in an interstitial position. Indeed, the lattice parameter $c$ (Table 1) of $\mathrm{TiO}_{2}: \mathrm{B}$, were shown to be larger than the ones of the reference $\mathrm{TiO}_{2}$ sample.

The unit cell volume in sample B is similar to the undoped $\mathrm{TiO}_{2}$ film synthesized under the same conditions. The extension of the $c$-axis and the expansion of the unit cell volume can be explained by the interstitial incorporation of boron in the $\mathrm{TiO}_{2}$ lattice. ${ }^{17,19}$ Raman spectroscopy studies of the as-synthesized samples (Figure $3 \mathrm{a}$ ) confirmed the presence of anatase $\mathrm{TiO}_{2}$ in the samples, following the characteristic bands at 144, 400, and $650 \mathrm{~cm}^{-1} \cdot{ }^{56}$ Doped $\mathrm{TiO}_{2}$ anatase samples are often characterized by a shift of the $\mathrm{E}_{\mathrm{g}}$ mode at 144 $\mathrm{cm}^{-1}$. 99,60 Close Inspection of Figure $3 \mathrm{~b}$, however, only showed a blue shift of the $E_{g}$ mode for sample $A$, allegedly the sample with the lowest boron content (Table 1). This observation seems to support our previous comments with regards of the actual B content in the samples, based on XPS and XRD results (vide supra). The suggested mechanism of formation of $\mathrm{TiO}_{2}$ from reaction between $\mathrm{TiCl}_{4}$ and ethyl acetate has been described according to the following equations: ${ }^{61}$

$$
\begin{aligned}
& \mathrm{CH}_{3} \mathrm{COOC}_{2} \mathrm{H}_{5} \rightarrow \mathrm{CH}_{3} \mathrm{CH}_{2} \mathrm{OH}+\mathrm{C}_{2} \mathrm{H}_{2} \mathrm{O} \\
& \mathrm{CH}_{3} \mathrm{CH}_{2} \mathrm{OH} \rightarrow \mathrm{H}_{2} \mathrm{O}+\mathrm{C}_{2} \mathrm{H}_{4} \\
& \mathrm{TiCl}_{4}+\mathrm{H}_{2} \mathrm{O} \rightarrow \mathrm{TiO}_{2}+\mathrm{HCl}
\end{aligned}
$$

These involve the decomposition of ethyl acetate to produce oxidizing species such as ethanol eq 1a), which in turn dehydrates into water and ethane (eq $1 \mathrm{~b}$. With water present, the surface reaction may proceed by hydrolysis of $\mathrm{TiCl}_{4}$ according to eq 1c. In the presence of triisopropyl borate, however, reaction with water may lead to boric acid following eq 2 .

$$
\mathrm{B}\left[\left(\mathrm{CH}_{3}\right)_{2} \mathrm{CHO}\right]_{3}+3 \mathrm{H}_{2} \mathrm{O} \rightarrow 3\left(\mathrm{CH}_{3}\right)_{2} \mathrm{CHOH}+\mathrm{H}_{3} \mathrm{BO}_{3}
$$

4.3. Morphology of the $\mathrm{TiO}_{2}: \mathrm{B}$ films. The mass flow rate of the boron precursor had a drastic impact on the morphology of the films. A typical SEM image of the undoped $\mathrm{TiO}_{2}$ film showed shell-shaped aggregated particles with sizes in the range of $120-230 \mathrm{~nm}$ (Figure 4a), which contrasted with the (a)

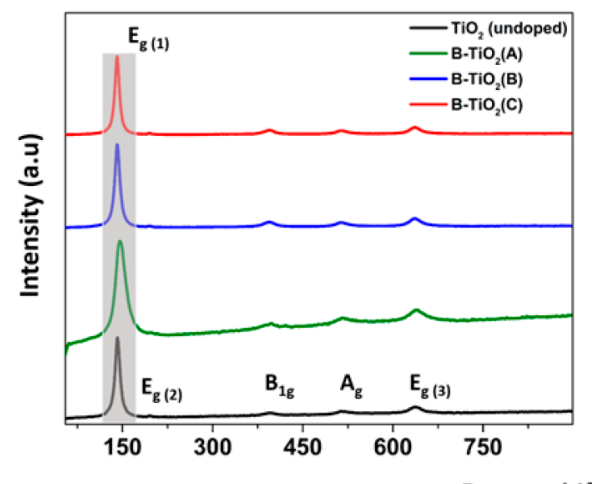

(b)

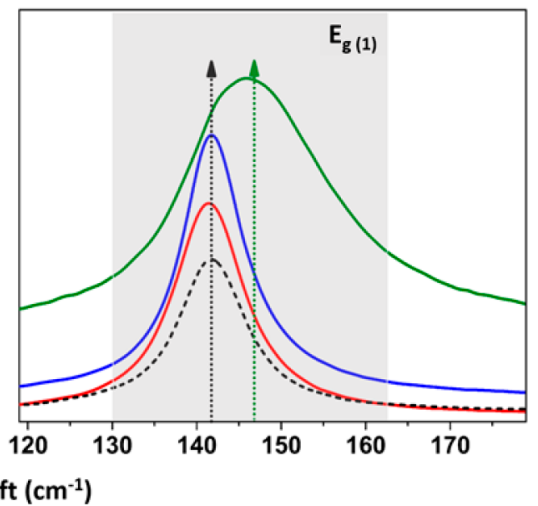

Figure 3. (a) Raman spectra of the $\mathrm{TiO}_{2}: \mathrm{B}$ samples, compared to the undoped anatase film and (b) Raman shift of the $E_{\mathrm{g}}$ band zoomed. Black dotted arrow (left) indicates the position of the undoped $\mathrm{TiO}_{2}$ and dotted green arrow (right) the position of the $E_{\mathrm{g}}(1)$ band for $\mathrm{TiO}_{2}(\mathrm{~A})$. 


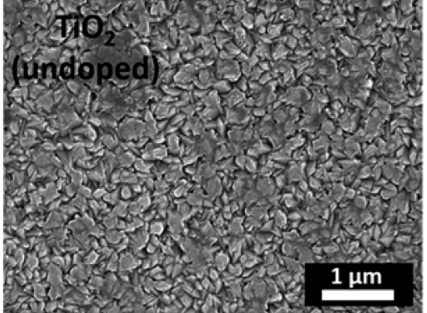

(a)

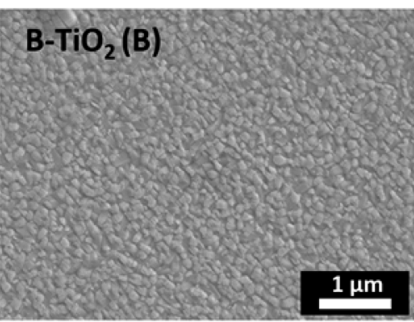

(c)

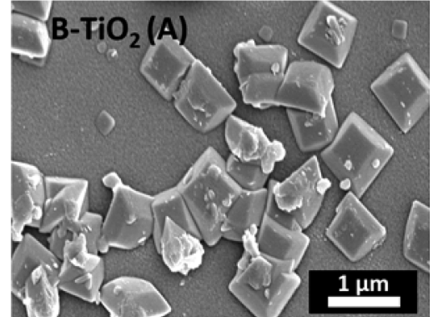

(b)

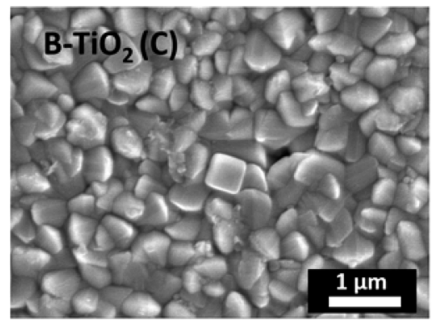

(d)

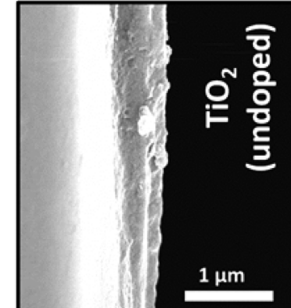

(e)

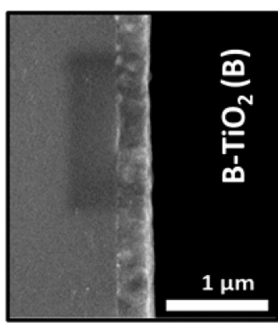

(g)

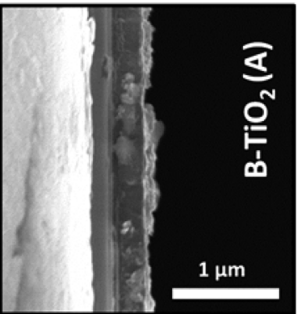

(f)

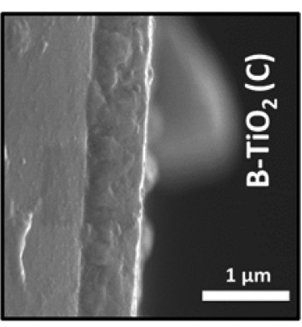

(h)

Figure 4. SEM images (top view): (a) Undoped $\mathrm{TiO}_{2},(\mathrm{~b}) \mathrm{TiO}_{2}: \mathrm{B}(\mathrm{A}),(\mathrm{c}) \mathrm{TiO}_{2}: \mathrm{B}(\mathrm{B})$, and (d) $\mathrm{TiO}_{2}: \mathrm{B}(\mathrm{C})$. Cross-section SEM images (e-h) of the undoped and boron-doped thin films, respectively.

(a)

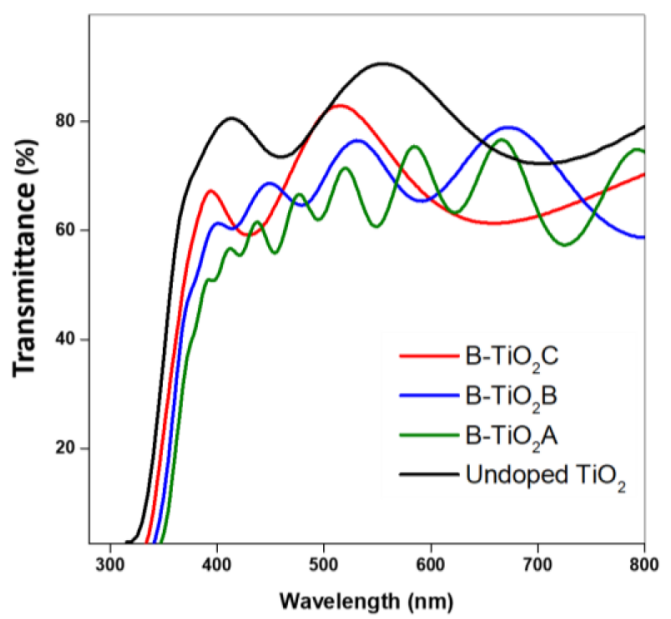

(b)

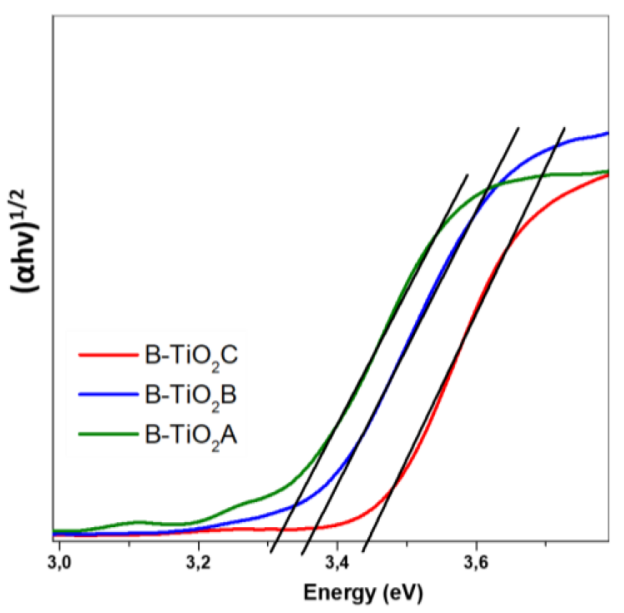

Figure 5. (a) UV-visible spectra (transmittance) of the doped and undoped $\mathrm{TiO}_{2}$ films and (b) graphical calculation (Tauc plot) of the optical band gap for all the boron-doped $\mathrm{TiO}_{2}$ samples.

significantly large average particle size of the $\mathrm{TiO}_{2}: \mathrm{B}$ samples. In Figure 4b, sample A showed agglomerations of big particles (ca. $1-2.3 \mu \mathrm{m}$ ) with a more defined prism-like and cubic shape deposited on top of a uniform coating of smaller agglomerations of particles. Both type of deposited particles were well adherent to the substrate forming a bilayer-like structure of $\mathrm{TiO}_{2}: \mathrm{B}$ as reported previously. ${ }^{19}$ In contrast, sample $\mathrm{B}$, exhibited a well-defined and uniform film composed of cubic-shaped particles (ca. $160 \mathrm{~nm}$ ). Sample C (Figure 4d) showed prism-shaped and well aggregated particles with sizes in the range of 300 to $500 \mathrm{~nm}$. Comparing the different surface morphologies of $\mathrm{TiO}_{2}: \mathrm{B}$ (Figure $4 \mathrm{~b}, \mathrm{c}$ and $\mathrm{d}$ ) with the undoped $\mathrm{TiO}_{2}$ film (Figure 4a), the final concentration of boron incorporation has a significant role in the agglomeration of the doped- $\mathrm{TiO}_{2}$ particles along the substrate. The SEM cross-section images of the samples (Figure $4 \mathrm{e}-\mathrm{h}$ ) show that both the undoped and doped $\mathrm{TiO}_{2}$ thin films described in this work were relatively hard and strongly adhered along the entirety of the glass substrate. In the case of sample $A$, the cross-section SEM analysis (Figure 4f) confirmed what can be seen in the top view image (Figure $4 \mathrm{~b}$ ), the multilayer-like morphology, where agglomerations of larger particles of $\mathrm{TiO}_{2}$ : $\mathrm{B}$ (cubic shape) can be found on top of a uniform layer of smaller particles. The thicknesses of the films were found to be in the range between 420 to $650 \mathrm{~nm} .{ }^{19}$

As it can be seen in Figure 4, the different $\mathrm{TiO}_{2}: \mathrm{B}$ films deposited showed varying morphology, associated with the boron doping level. SEM observations supported the existence of morphology discrepancies between the $\mathrm{TiO}_{2}$ : $\mathrm{B}$ samples (Figure $4 b, c$ and $d$ ) and the undoped $\mathrm{TiO}_{2}$ coatings (Figure 4a). In addition, SEM analysis of the $\mathrm{TiO}_{2}: \mathrm{B}$ samples revealed the presence of 3 different morphologies which correspond to the macroscopic aspect variation observed on the substrate (Figure S1), i.e., visual observations under tilt angle of sample A presented areas containing concentric circles whereas sample $\mathrm{B}$ and $\mathrm{C}$ showed different lines of interference colors, 
(a)

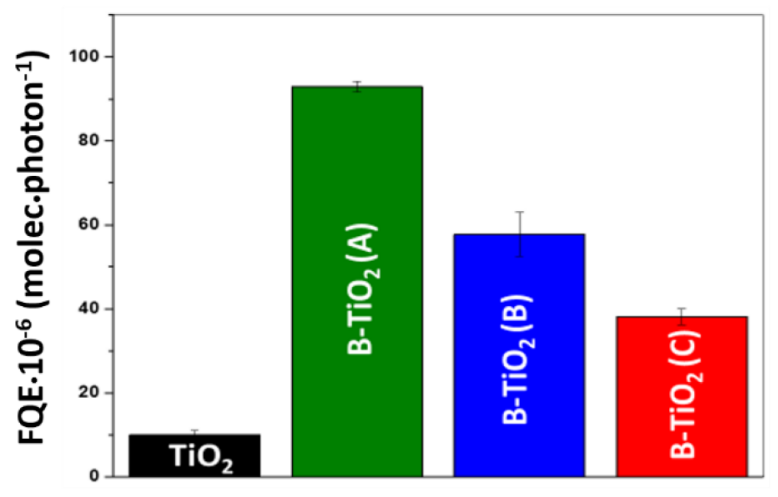

(b)

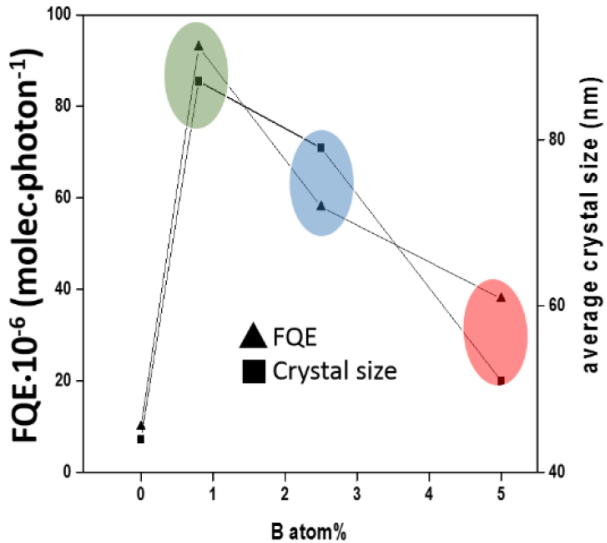

Figure 6. (a) Formal quantum efficiencies (FQE) obtained during photodegradation of stearic acid under UVA irradiation of undoped and borondoped $\mathrm{TiO}_{2}$ films. (b) Comparison between photocatalytic activities and crystallite sizes as determined from XRD analysis. Crystal size data presented in Table 1 .

Table 2. Data extracted from the Hall Effect Electrical Measurements. (*) From ref 35:

\begin{tabular}{|c|c|c|c|c|}
\hline \multirow[b]{2}{*}{ sample } & \multicolumn{3}{|c|}{ Hall effect probe } & \multirow{2}{*}{$\frac{\text { resistance }}{R(\mathrm{~K} \Omega)}$} \\
\hline & $n\left(\mathrm{~cm}^{-3}\right)$ & $\mu\left(\mathrm{cm}^{2} \mathrm{~V}^{-1} \mathrm{~s}^{-1}\right)$ & $\rho(\Omega \mathrm{cm})$ & \\
\hline $\mathrm{TiO}_{2}: \mathrm{B}(\mathrm{A})$ & $-3.24 \times 10^{15}$ & 172.40 & 112 & $150 \pm 3$ \\
\hline $\mathrm{TiO}_{2}: \mathrm{B}(\mathrm{B})$ & $-3.82 \times 10^{17}$ & 8.17 & 20 & $90 \pm 1$ \\
\hline $\mathrm{TiO}_{2}: \mathrm{B}(\mathrm{C})$ & $-9.00 \times 10^{13}$ & 0.08 & $9.5 \times 10^{5}$ & $120 \pm 5$ \\
\hline $\mathrm{Nb}: \mathrm{TiO}_{2}{ }^{(*)}$ & $-8.30 \times 10^{18}$ & 3.4 & 0.22 & - \\
\hline $\mathrm{F}: \mathrm{TiO}_{2}{ }^{(*)}$ & -46.00 & 26 & 5.2 & - \\
\hline
\end{tabular}

expressing thickness differences along the length of the substrate. $^{19}$

4.4. Optical Properties of the Films. The undoped $\mathrm{TiO}_{2}$ thin films displayed high optical transparency. The incorporation of low B concentrations (sample A, $\sim 1$ at. \%) resulted in films with zones of concentric circles on the substrate evidenced by a red shift in the transmission onset from 316 to $348 \mathrm{~nm}$ compared to the undoped $\mathrm{TiO}_{2}$ thin films (Figure 5a). Surprisingly, the shift was not so drastic for the highly doped films (samples B and C). These results are similar to phosphorus doped $\mathrm{TiO}_{2}$ thin films by C. Sotelo-Vazquez et al., ${ }^{60}$ where it was reported a small shift (blue shift in their case) when the concentration of the dopant (phosphorus) was lower than 1 at. \%, and no noticeable shift occurs when the concentration was higher than 1 at. \%.

Tauc plot analysis (Figure 5b) showed a slight shift in absorption into the blue region for the doped $\mathrm{TiO}_{2}$ samples compared to the experimental value for undoped films $(\sim 3.45$ $\mathrm{eV}$ ), with band gap energies estimated around 3.28, 3.36, and $3.43 \mathrm{eV}$ for samples A, B, and C, respectively. Valence band XPS (VB-XPS) shows the valence band edge relative to the Fermi level for the undoped and boron-doped $\mathrm{TiO}_{2}$ samples (Figure S6), corroborating the band gap shifts.

4.5. Functional Properties of the $\mathrm{TiO}_{2}: \mathrm{B}$ Films. The photocatalytic properties of the $\mathrm{TiO}_{2}: \mathrm{B}$ films were investigated during degradation of stearic acid under UVA and visible light irradiation. ${ }^{23}$ Figure 6 a shows the corresponding photocatalytic activities under UVA light $\left(2 \mathrm{~mW} \cdot \mathrm{cm}^{-2}\right)$, expressed in terms of formal quantum efficiency (FQE), which is defined as molecules of stearic acid degraded over incident photons (molecule/photon). All the $\mathrm{TiO}_{2}: \mathrm{B}$ samples showed improved photocatalytic activities compared to a conventional undoped anatase $\mathrm{TiO}_{2}$ film. This is not surprising considering that the incorporation of interstitial boron encouraged crystallinity (Figure 2) and increased crystallite size (Table 1). This is certainly the case for the incorporation of relatively low levels of boron in the structure $(\sim 1$ at\%) as observed for sample A. The synthesis conditions in the presence of higher concentrations of boron precursor induced lower crystallite sizes for samples B and C, respectively, and the photocatalytic activities were observed to follow the same trend (Figure $6 \mathrm{~b}$ ). Nevertheless, as seen in the XRD patterns (Figure $2 \mathrm{~d}$ ) the boron-doped $\mathrm{TiO}_{2}$ sample $\mathrm{C}$ contains simultaneously rutile and anatase. The presence of rutile has been also reported to have a direct impact in the photocatalytic performance of $\mathrm{TiO}_{2}$. Reported by Scanlon et al., ${ }^{44}$ photogenerated conduction electrons will flow from rutile to anatase, inducing a type II band alignment $(\sim 0.4 \mathrm{eV})$, significantly reducing the effective bandgap of composite materials, and improving efficient electron- hole separation. This alignment increased the photoactivity of anatase-rutile composite materials over their individual analogues.

The conductivity of the doped films was also investigated using a Hall Effect probe and the results are summarized in Table 2. As the resistivity was close to the detection limits of the Hall Effect device, the derived charge carrier densities and mobilities were liable to have large associated errors. A high resistivity and small range of mobility of the charge carriers was measured. It was found that the lowest resistivity was found for sample B $(20 \Omega \mathrm{cm})$ while the highest was for sample C $(9.5 \times$ $10^{5} \Omega \mathrm{cm}$ ). Comparing these values to $\mathrm{Nb}: \mathrm{TiO}_{2}$ and $\mathrm{F}: \mathrm{TiO}_{2}$, the measured values of resistance $(\boldsymbol{\rho})$ for $\mathrm{TiO}_{2}: \mathrm{B}$ are much higher. 
4.6. Bulk Electronic Properties. The density of states (DoS) and band structure for anatase $\mathrm{TiO}_{2}$ are presented in Figure 7, parts a and $b$ respectively. The DoS shows that the

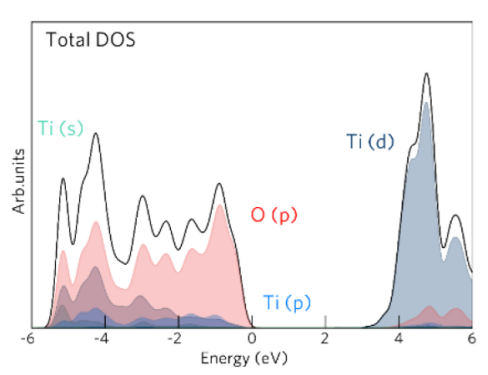

(a)

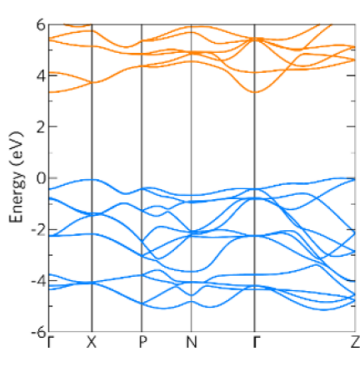

(b)
Figure 7. Calculated density of states (DoS) (a) and band structure (b) of undoped anatase $\mathrm{TiO}_{2}$. In each diagram the valence band maximum (VBM) is set to $0 \mathrm{eV}$. In part $\mathrm{b}$, the valence bands are depicted as blue lines and the conduction bands as orange lines.

VBM is predominantly made up of $\mathrm{O} 2 \mathrm{p}$ states mixed with some negligible Ti $p$ and $d$ states. On the other hand, the CBM is mostly made up of Ti $\mathrm{d}$ states alongside a minimal amount of $\mathrm{O}$ states. These results are consistent with other DFT calculations on $\mathrm{TiO}_{2}$ polymorphs. ${ }^{44,62}$ Figure $7 \mathrm{~b}$ shows that anatase is an indirect band gap material $\left(E_{\mathrm{g}}\right.$ ind $\left.=3.35 \mathrm{eV}\right)$ with the VBM occurring just off the $Z$ high symmetry point (between $\Gamma$ and $Z$ ) and the CBM at $\Gamma$. The direct band gap at $\Gamma$ has a magnitude of $3.64 \mathrm{eV}$. These results are consistent with other theoretical calculations using HSE06 ${ }^{63,64}$ and low temperature optical studies $(3.42 \mathrm{eV}){ }^{65}$ however the general consensus in experiment places the band gap at $\sim 3.2 \mathrm{eV}^{44}$ Higher levels of theory such as the GW (Green's function) approximation which place the band gap around 3.6-3.8 $\mathrm{eV}{ }^{66-69}$ the overestimation is generally thought to be excitonic effects or the difficulties in the convergence of the screened interaction of localized systems. ${ }^{67-69}$

4.7. Defect Thermodynamics. Figure 8 shows the transition level diagrams for $\mathrm{TiO}_{2}: \mathrm{B}$ under both Ti-rich/Opoor and Ti-poor/O-rich conditions.

4.7.1. Intrinsic Defects. Previous theoretical studies have shown that the dominant acceptor and donor defects in anatase are the titanium vacancy $\left(V_{\mathrm{Ti}}\right)$ and the oxygen vacancy $\left(V_{\mathrm{O}}\right) .{ }^{46,48,70-73}$ Under Ti-rich/O-poor conditions, $V_{\mathrm{O}}$ acts as a resonant donor with a low formation energy (for $V_{\mathrm{O}}{ }^{0}, \Delta H_{\mathrm{f}}=\sim$ $1.19 \mathrm{eV}$ ) with the $2+$ charge state dominant across the entirety of the band gap. This is in contrast to most wide band gap binary oxides such as such as $\mathrm{ZnO},{ }^{34,74-76} \mathrm{SnO}_{2}{ }^{76-79}$ $\mathrm{In}_{2} \mathrm{O}_{3},{ }^{42,76,80-83}$ and $\mathrm{BaSnO}_{3}{ }^{84}$ where $V_{\mathrm{O}}$ is a "negative- $\mathrm{U}$ " defect modulating from the $2+$ to the neutral charge state in the band gap. Under Ti-poor/O-rich conditions, $V_{\mathrm{O}}$ has a higher formation energy $\left(\Delta H_{\mathrm{f}}=\sim 4.71 \mathrm{eV}\right)$. These results are consistent with other theoretical studies carried out on anatase. $^{48,70,85,86}$

$V_{\mathrm{Ti}}$ is a deep acceptor under both growth regimes with the 1-/0 transition level occurring at $\sim 0.87 \mathrm{eV}$ above the VBM. The formation energies of the neutral charge state occur at $\sim 14.26$ and $\sim 7.23 \mathrm{eV}$ for Ti-rich/O-poor and Ti-poor/O-rich conditions respectively, meaning that the formation of $V_{\mathrm{Ti}}$ near the VBM is highly unfavorable and will be seen in negligible quantities. Under Ti-poor/O-rich conditions ( $p$-type favorable), $V_{\mathrm{Ti}}{ }^{4-}$ begins compensating the donor defects $\sim 2.28 \mathrm{eV}$ above the VBM. Our calculations show that all charge states of $V_{\mathrm{Ti}}$ are shown in the band gap. Multiple pictures of $V_{\mathrm{Ti}}$ are seen in the theoretical literature on anatase. Phattalung et al. ${ }^{87}$ found using LDA (Local Density Approximation) that $V_{\mathrm{Ti}}$ is a quadruple shallow acceptor, however LDA is known to be inadequate in describing the band gap and correct localization of holes and electrons. Applying a Hubbard-like " $U$ " value (which incorporates an occupation penalty scheme), Morgan et al. show that $V_{\mathrm{Ti}}$ is a deep acceptor (2-/0 transition occurs $\sim 0.85 \mathrm{eV}$ above the VBM). In this study, however, it is shown that there is no $0 / 1-$ transition level and the formation energy is $\sim 2.5 \mathrm{eV}$ lower than that calculated from our calculations. ${ }^{70,73}$ The only HSE06 calculations on $V_{\mathrm{Ti}}$ in anatase show that the defect transitions from the neutral charge state to the 2- and then the 4- charge state over the band gap. In these calculations, only a Monkhorst-Pack $1 \times 1 \times 1 k$-point sampling was used which can lead to inaccurate total energies and therefore uncertainty in the thermodynamic picture of the defects. $^{48}$

It is known that the thermodynamic transition levels can be sensitive to the correct localization and delocalization of electrons and holes and Figure 9 presents the calculated partial
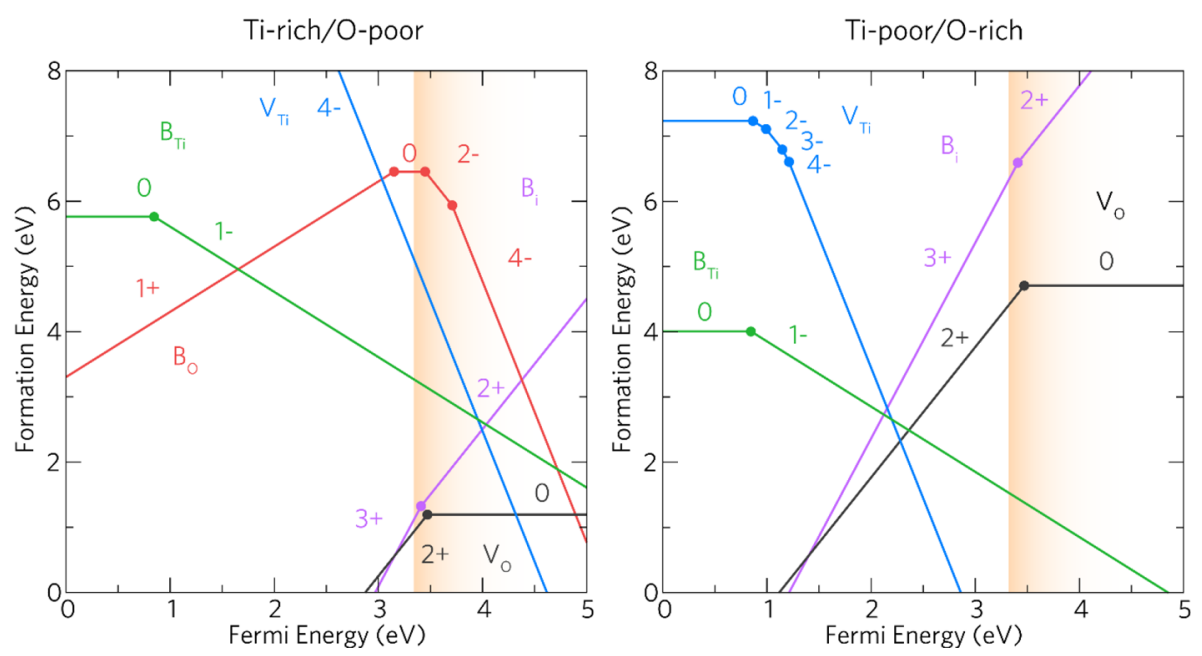

Figure 8. Transition level diagrams for $\mathrm{TiO}_{2}: \mathrm{B}$ under both Ti-rich/O-poor (left) and Ti-poor/O-rich (right) growth regimes. The Fermi energy goes from the VBM $(0 \mathrm{eV})$ to $1.7 \mathrm{eV}$ above the CBM (which is at $3.35 \mathrm{eV}$ ). The conduction band region is shown by the graded area. 

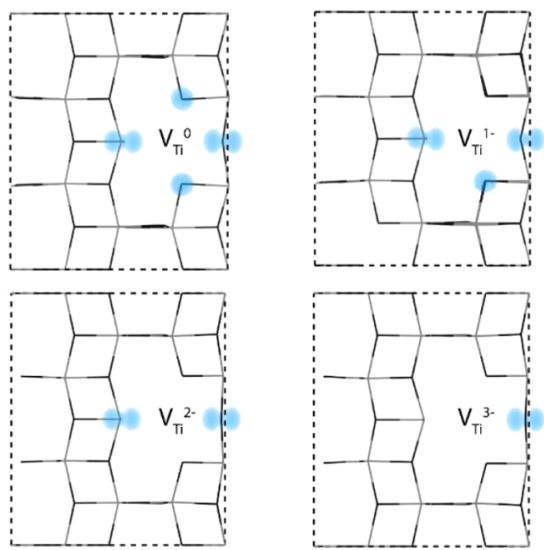

Figure 9. Partial charge densities of the charge states of $\mathrm{V}_{\mathrm{Ti}}$ as viewed along the $\{010\}$ direction showing the localization of holes (blue isosurfaces) in each example. The isosurfaces are plotted from 0$0.015 \mathrm{eV} \AA^{-3}$.

charge densities of each charge state of $V_{\mathrm{Ti}}$ displaying the correct localization of holes on the adjacent oxygens surrounding the vacancy. The axial holes are the first to be removed $\left(V_{\mathrm{Ti}}{ }^{-}\right.$and $V_{\mathrm{Ti}}{ }^{2-}$ which are depicted as $\mathrm{p}_{y}$ orbitals $)$ and then the equatorial holes $\left(V_{\mathrm{Ti}}{ }^{3-}\right.$ and $V_{\mathrm{Ti}}{ }^{4-}$ depicted as $\mathrm{p}_{z}$ orbitals). This correct localization is important and we have shown this to be as important in $\mathrm{ZnO}{ }^{88}$

4.7.2. B-Doping. Boron can enter the anatase lattice interstitially $\left(\mathrm{B}_{\mathrm{i}}\right)$ or substitutionally on a titanium site $\left(\mathrm{B}_{\mathrm{Ti}}\right)$ or oxygen site $\left(\mathrm{B}_{\mathrm{O}}\right)$. Previous theoretical studies have been carried out on $\mathrm{TiO}_{2}: \mathrm{B}^{16,89-93}$ in particular, a study by $\mathrm{E}$. Finazzi and co-workers ${ }^{18}$ which gives a fairly comprehensive view on the electronic structure of various $B$ related defects.

Under Ti-rich/O-poor conditions, $\mathrm{B}_{\mathrm{i}}^{3+}$ is lowest in energy across the whole band gap, meaning that interstitial boron is the most preferential dopant state to form. $B_{i}$ acts as a shallow dopant donating 3 electrons into the conduction band and has a very low formation energy. The Fermi level is pinned in the conduction band at $\sim 0.65 \mathrm{eV}$ above the CBM when the $V_{\mathrm{Ti}}{ }^{4-}$ charge state falls low enough in formation energy to begin compensation of the donated electrons. Under Ti-poor/O-rich conditions, the formation energy of $B_{i}$ is raised in energy and the Fermi level is pinned in the band gap $\sim 2 \mathrm{eV}$ above the VBM when $\mathrm{B}_{\mathrm{Ti}}{ }^{-}$and $\mathrm{V}_{\mathrm{Ti}}{ }^{4-}$ cross those of $\mathrm{B}_{\mathrm{i}}^{3+}$ and $V_{\mathrm{O}}{ }^{2+}$. In parts a-c of Figure 10, the partial charge localization is shown for $B_{i}$ in the $0,1+$ and $2+$ charge states.

$B_{i}$ is a three electron donor; however, when it reaches the 0 and $1+$ charge states $(\sim 2.42 \mathrm{eV}$ above the CBM) (Figure 10, parts $a$ and $b$ ), the donated electrons start to become highly localized on the B and adjacent $\mathrm{Ti}$ atoms, this has also been seen previously by Yang et al. ${ }^{90}$ the $2+$ charge state is shows a delocalized electron (Figure 10c).

$\mathrm{B}_{\mathrm{Ti}}$ has a high formation energy under Ti-rich/O-poor $\left(\mathrm{B}_{\mathrm{Ti}}{ }^{0}\right.$ occurs $\sim 5.76 \mathrm{eV}$ ) where self-compensation is observed when $\mathrm{B}_{\mathrm{Ti}}{ }^{-}$crosses the $\mathrm{B}_{\mathrm{i}}{ }^{3+}$ line at $\sim 2.12 \mathrm{eV}$ above the VBM. Under Ti-poor/O-rich conditions, p-type defect favorable conditions, $\mathrm{B}_{\mathrm{Ti}}$ is still relatively high in energy $(\sim 4 \mathrm{eV})$. The $1-/ 0$ transition level occurs at $\sim 0.85 \mathrm{eV}$ above the VBM, making this defect a very deep acceptor so no p-type capability should be seen.

Under Ti-rich/O-poor conditions, $\mathrm{B}_{\mathrm{Ti}}$ begins to selfcompensate $\sim 2.12 \mathrm{eV}$ above the VBM. Previous calculations have stated that $\mathrm{B}_{\mathrm{Ti}}$ is the least favorable substitional
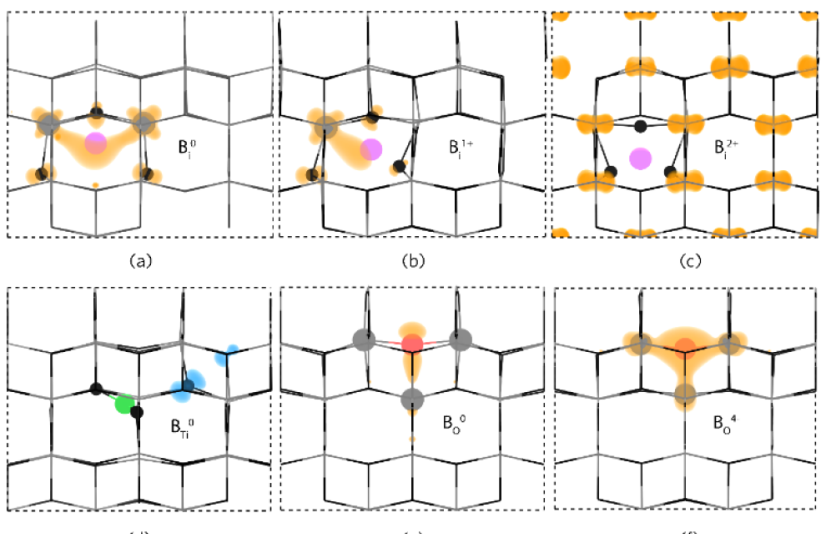

(1)

Figure 10. Partial charge densities of $\mathrm{B}_{\mathrm{i}}^{0}(\mathrm{a}), \mathrm{B}_{\mathrm{i}}{ }^{1+}(\mathrm{b}), \mathrm{B}_{\mathrm{i}}{ }^{2+}(\mathrm{c}), \mathrm{B}_{\mathrm{Ti}}{ }^{0}$ $(\mathrm{d}), \mathrm{B}_{\mathrm{O}}{ }^{0}(\mathrm{e})$, and $\mathrm{B}_{\mathrm{O}}{ }^{4-}$ (f) defect charge states as viewed along the $\{100\}$ direction displaying the localization of holes and electrons (blue and orange isosurfaces respectively). The isosurfaces are plotted from 0 to $0.015 \mathrm{eV}^{-3}$.

defect, ${ }^{89,92}$ however we find the opposite is true. $\mathrm{B}_{\mathrm{Ti}}{ }^{0}$ distorts from the Ti site by up to $\sim 11 \%$ in the $b$ direction forming a trigonal planar $\mathrm{BO}_{3}$. The hole is localized on an adjacent $\mathrm{O}$ as shown in Figure 10d, with the distortion clearly visible. In the 1 - charge state, the B moves back toward the original Ti site now that the hole is removed reforming a tetrahedral $\mathrm{BO}_{4}$.

The last defect to be considered is $\mathrm{B}_{\mathrm{O}}$ which acts as a slightly deep donor with the $1+/ 0$ transition level occurring at $\sim 0.20$ $\mathrm{eV}$ below the CBM. Under Ti-rich/O-poor conditions $\mathrm{B}_{\mathrm{O}}$ forms at a high energy $(\sim 6.45 \mathrm{eV})$, and under Ti-poor/O-rich conditions, this rises to $\sim 15.23 \mathrm{eV}$. Beyond the CBM $\mathrm{B}_{\mathrm{O}}$ quickly becomes an acceptor changing to the 2- charge state $\sim 0.1 \mathrm{eV}$ above the CBM then to the $4-$ charge state $\sim 0.36 \mathrm{eV}$ above the CBM.

Under Ti-rich/O-poor conditions $\mathrm{B}_{\mathrm{O}}$ becomes the dominant boron defect $\sim 1.37 \mathrm{eV}$ above the CBM. The partial charge density of the neutral and 4- charge states are shown in Figures 10 , parts e and $\mathrm{f}$, where localization is seen shared between the boron atom and the titanium atom below it.

Accounts by Finazzi and co-workers see an almost identical picture, however with more localization on the $\mathrm{Ti}$, which could be an artifact from using a $\Gamma$-point only calculation. Less distortion is seen here than for $\mathrm{B}_{\mathrm{Ti}}$ although in the neutral charge state $\mathrm{B}$ distorts $\sim 5 \%$ in the c direction while the $\mathrm{Ti}$ below shifts $\sim 4 \%$ from its original position away from the defect. The 4- charge state displays a quadruple polaron (shown in Figure 10f) and the atoms shift back toward their original positions $\left(\sim 2 \%\right.$ from $\left.\mathrm{B}_{\mathrm{Ti}}^{0}\right)$.

\section{CONCLUSIONS}

A series of interstitial boron-doped anatase $\mathrm{TiO}_{2}$ of different concentrations were synthesized and deposited on glass by one-step APCVD. The concentration of the dopant (from 1 to 5 at. \% B) was varied by increasing the mass flow rate of boron isopropoxide and varying the temperature of the bubbler where it was placed. Anatase was obtained in all of the $\mathrm{TiO}_{2}: \mathrm{B}$ samples. In the case of sample $\mathrm{C}$, when a higher mass flow of boron was used, rutile was formed along with a powdery deposition on top of some areas of the film. The powdery deposition was easily removed and was characterized as a mixture of anatase and a form of boric acid $\left(\mathrm{H}_{3} \mathrm{BO}_{3}\right)$, called sassolite. Proven by XPS and D-SIMS, boron was incorporated 
in $\mathrm{TiO}_{2}$ as an interstitial, that form being the most stable of boron-doped $\mathrm{TiO}_{2}{ }^{15,17}$ The incorporation of interstitial boron induced a noticeable change in the morphology of the dopedfilms and in the average particle size, more remarkable in the case of sample $\mathrm{TiO}_{2}: \mathrm{B}$ (A). The optical band gap slightly changed but no visible light absorption/response was found. The photocatalytic performance of $\mathrm{TiO}_{2}: \mathrm{B}$ films under UV was enhanced, being much higher and noticeable in the case of sample A, which contains around 1 at. \% B. Surprisingly, boron-doped $\mathrm{TiO}_{2}$ samples presented certain conductivity and electron mobility, proven by multimeter and Hall Effect measurements.

From our theoretical and computational analyses, we show that in the likely event of $B_{i}$ forming, the material will be made n-type under Ti-rich/O-poor conditions, explaining the n-type conductivity measured. $\mathrm{B}_{\mathrm{i}}{ }^{3+}$ is the most preferential dopant state to form. Under Ti-poor/O-rich conditions the Fermi level will be trapped $\sim 2 \mathrm{eV}$ above the $\mathrm{VBM}$, indicating that electrons trapped at this level could be excited by visible light into the CBM thus increasing the visible light activity. In addition, we can conclude that an excessive addition of boron during the synthesis of the interstitial $\mathrm{TiO}_{2}: \mathrm{B}$ thin films is detrimental for the formation of the films, affecting the nucleation process and increasing the gas phase reaction that leads to a powdery deposition, as well as for the photocatalytic properties of $\mathrm{TiO}_{2}: \mathrm{B}$, which after reaching the optimal concentration $(\sim 1$ at. $\%)$ the photocatalytic performance of the interstitial boron-doped $\mathrm{TiO}_{2}$ samples decreases.

The data obtained by XRD, Raman spectroscopy and XPS data, indicated that (i) boron has been implanted within the anatase phase interstitially, and (ii) when the mass flow of the dopant is too high, the rutile phase appears and a powdery phase-mixture of $\mathrm{TiO}_{2}$ and $\mathrm{H}_{3} \mathrm{BO}_{3}$ (sassolite) is deposited along with the film as byproducts, which can be found in some areas of the substrate (glass).

\section{ASSOCIATED CONTENT}

\section{S Supporting Information}

The Supporting Information is available free of charge on the ACS Publications website at DOI: 10.1021/acs.jpcc.7b11142.

Table containing experimental parameters of the deposition, photos of the films, PXRD pattern of powdery deposition, $\mathrm{Ti} 2 \mathrm{p}$ environment surface XPS spectrum of sample $\mathrm{TiO}_{2}: \mathrm{B}(\mathrm{B})$, depth profile D-SIMS spectra of all boron-doped samples, photo of a $\mathrm{TiO}_{2}: \mathrm{B}$ thin film while testing resistance by a multimeter, FTIR spectra of the decomposition of SA in sample A, and valence band XPS spectra of all samples (PDF)

\section{AUTHOR INFORMATION}

\section{Corresponding Author}

*(I.P.P.) E-mail: i.p.parkin@ucl.ac.uk.

\section{ORCID $\odot$}

Miguel Quesada-Gonzalez: 0000-0003-2675-3580

Andreas Kafizas: 0000-0002-2282-4639

Nicolas D. Boscher: 0000-0003-3693-6866

David O. Scanlon: 0000-0001-9174-8601

Claire J. Carmalt: 0000-0003-1788-6971

\section{Author Contributions}

All authors have given approval to the final version of the manuscript.

\section{Funding}

UCL Chemistry Department is thanked for funding and support through Grant 510300.

\section{Notes}

The authors declare no competing financial interest.

\section{ACKNOWLEDGMENTS}

This work made use of the ARCHER U.K. National Supercomputing Service (http://www.archer.ac.uk) via our membership in the U.K.'s HEC Materials Chemistry Consortium, which is also funded by the EPSRC (EP/ L000202). The UCL Legion and Grace HPC Facilities (Legion@UCL and Grace@UCL) were also used in the completion of this work. D.O.S. would like to acknowledge support from the EPSRC (EP/N01572X/1). Dr. F. Di Maggio, Dr. S. Sathasivam, and Dr. C. Knapp are thanked for useful discussions. Dr. Robert Palgrave is also thanked for access and assistance with the XPS instrument.

\section{ABBREVIATIONS}

APCVD, atmospheric pressure chemical vapor deposition; FQE, formal quantum efficiency

\section{REFERENCES}

(1) Fujishima, A.; Zhang, X.; Tryk, D. A. $\mathrm{TiO}_{2}$ Photocatalysis and Related Surface Phenomena. Surf. Sci. Rep. 2008, 63, 515-582.

(2) Kafizas, A.; Parkin, I. P. Combinatorial Atmospheric Pressure Chemical Vapor Deposition (cAPCVD): A Route to Functional Property Optimization. J. Am. Chem. Soc. 2011, 133, 20458-20467.

(3) Mills, A.; Le Hunte, S. An Overview of Semiconductor Photocatalysis. J. Photochem. Photobiol., A 1997, 108, 1-35.

(4) Velten, D.; Biehl, V.; Aubertin, F.; Valeske, B.; Possart, W.; Breme, J. Preparation of $\mathrm{TiO}_{2}$ Layers on $\mathrm{Cp}-\mathrm{Ti}$ and $\mathrm{Ti}_{6} \mathrm{Al}_{4} \mathrm{~V}$ by Thermal and Anodic Oxidation and by Sol-Gel Coating Techniques and Their Characterization. J. Biomed. Mater. Res. 2002, 59, 18-28.

(5) Carlsson, J. Chemical Vapor Deposition. Handb. Depos. Technol. Film. Coatings 2010, 314-363.

(6) Zaleska, A. Doped-TiO 2 : A Review. Recent Pat. Eng. 2008, 2, 157-164; 2008, 2, 157-164.

(7) Guillot, J.; Lecoq, E.; Duday, D.; Puhakka, E.; Riihimäki, M.; Keiski, R.; Chemin, J.-B.; Choquet, P. Combining a Molecular Modelling Approach with Direct Current and High Power Impulse Magnetron Sputtering to Develop New $\mathrm{TiO}_{2}$ Thin Films for Antifouling Applications. Appl. Surf. Sci. 2015, 333, 186-193.

(8) Burda, C.; Chen, X.; Narayanan, R.; El-Sayed, M. A. Chemistry and Properties of Nanocrystals of Different Shapes. Chem. Rev. 2005, 105, 1025-1102.

(9) Kafizas, A.; Kellici, S.; Darr, J. A.; Parkin, I. P. Titanium Dioxide and Composite Metal/metal Oxide Titania Thin Films on Glass: A Comparative Study of Photocatalytic Activity. J. Photochem. Photobiol., A 2009, 204, 183-190.

(10) Choy, K. Chemical Vapour Deposition of Coatings. Prog. Mater. Sci. 2003, 48, 57-170.

(11) O’Neill, S.; Parkin, I. P.; Clark, R. J. H.; Mills, A.; Elliott, N. Photocatalytically Active $\mathrm{WO}_{3}$ Films from the Atmospheric Pressure CVD of $\mathrm{WOCl}_{4}$ with Ethyl Acetate or Ethanol. Chem. Vap. Deposition 2004, 10, 136-141.

(12) Bhachu, D. S.; Sathasivam, S.; Sankar, G.; Scanlon, D. O.; Cibin, G.; Carmalt, C. J.; Parkin, I. P.; Watson, G. W.; Bawaked, S. M.; Obaid, A. Y.; Al-Thabaiti, S.; Basahel, S. N. Solution Processing Route to Multifunctional Titania Thin Films: Highly Conductive and Photcatalytically Active $\mathrm{Nb}: \mathrm{TiO}_{2}$. Adv. Funct. Mater. 2014, 24, 50755085.

(13) Tseng, T. K.; Lin, Y. S.; Chen, Y. J.; Chu, H. A Review of Photocatalysts Prepared by Sol-Gel Method for VOCs Removal. Int. J. Mol. Sci. 2010, 11, 2336-2361. 
(14) Quesada-Cabrera, R.; Sotelo-Vazquez, C.; Darr, J. A.; Parkin, I. P. Critical Influence of Surface Nitrogen Species on the Activity of NDoped $\mathrm{TiO}_{2}$ Thin-Films during Photodegradation of Stearic Acid under UV Light Irradiation. Appl. Catal., B 2014, 160-161, 582-588.

(15) Zaleska, A.; Grabowska, E.; Sobczak, J. W.; Gazda, M.; Hupka, J. Photocatalytic Activity of Boron-Modified $\mathrm{TiO}_{2}$ under Visible Light: The Effect of Boron Content, Calcination Temperature and $\mathrm{TiO}_{2}$ Matrix. Appl. Catal., B 2009, 89, 469-475.

(16) Finazzi, E.; Di Valentin, C.; Pacchioni, G. Boron-Doped Anatase $\mathrm{TiO}_{2}$ : Pure and Hybrid DFT Calculations. J. Phys. Chem. C 2009, 113, 220-228.

(17) Patel, N.; Dashora, A.; Jaiswal, R.; Fernandes, R.; Yadav, M.; Kothari, D. C.; Ahuja, B. L.; Miotello, A. Experimental and Theoretical Investigations on the Activity and Stability of Substitutional and Interstitial Boron in $\mathrm{TiO}_{2}$ Photocatalyst. J. Phys. Chem. C 2015, 119, 18581-18590.

(18) Carmichael, P.; Hazafy, D.; Bhachu, D. S.; Mills, A.; Darr, J. A.; Parkin, I. P. Atmospheric Pressure Chemical Vapour Deposition of Boron Doped Titanium Dioxide for Photocatalytic Water Reduction and Oxidation. Phys. Chem. Chem. Phys. 2013, 15, 16788-16794.

(19) Quesada-Gonzalez, M.; Boscher, N. D.; Carmalt, C. J.; Parkin, I. P. Interstitial Boron-Doped $\mathrm{TiO}_{2}$ Thin Films: The Significant Effect of Boron on $\mathrm{TiO}_{2}$ Coatings Grown by Atmospheric Pressure Chemical Vapor Deposition. ACS Appl. Mater. Interfaces 2016, 8, 25024-25029.

(20) O’Neill, S. A.; Parkin, I. P.; Clark, R. J. H.; Mills, A.; Elliott, N. Atmospheric Pressure Chemical Vapour Deposition of Titanium Dioxide Coatings on Glass. J. Mater. Chem. 2003, 13, 56-60.

(21) Toby, B. H. EXPGUI, a Graphical User Interface for GSAS. J. Appl. Crystallogr. 2001, 34, 210-213.

(22) Swanepoel, R. Determination of the Thickness and Optical Constants of Amorphous Silicon. J. Phys. E: Sci. Instrum. 1983, 16, 1214-1222.

(23) Mills, A.; Wang, J. Simultaneous Monitoring of the Destruction of Stearic Acid and Generation of Carbon Dioxide by Self-Cleaning Semiconductor Photocatalytic Films. J. Photochem. Photobiol., A 2006, 182, 181-186.

(24) Kresse, G.; Hafner, J. Ab Initio Molecular Dynamics for Liquid Metals. Phys. Rev. B: Condens. Matter Mater. Phys. 1993, 47, 558-561.

(25) Kresse, G.; Hafner, J. Ab-Initio Molecular-Dynamics Simulation of the Liquid-Metal Amorphous-Semiconductor Transition in Germanium. Phys. Rev. B: Condens. Matter Mater. Phys. 1994, 49, 14251-14269.

(26) Kresse, G.; Furthmüller, J. Efficiency of Ab-Initio Total Energy Calculations for Metals and Semiconductors Using a Plane-Wave Basis Set. Comput. Mater. Sci. 1996, 6 (1), 15-50.

(27) Kresse, G.; Furthmüller, J. Efficient Iterative Schemes for Ab Initio Total-Energy Calculations Using a Plane-Wave Basis Set. Phys. Rev. B: Condens. Matter Mater. Phys. 1996, 54, 11169.

(28) Blochl, P. E. Projector Augmented-Wave Method. Phys. Rev. B: Condens. Matter Mater. Phys. 1994, 50, 17953-17979.

(29) Paier, J.; Marsman, M.; Hummer, K.; Kresse, G.; Gerber, I. C.; Ángyán, J. G. Screened Hybrid Density Functionals Applied to Solids. J. Chem. Phys. 2006, 124, 154709.

(30) Heyd, J.; Scuseria, G. E.; Ernzerhof, M. Hybrid Functionals Based on a Screened Coulomb Potential. J. Chem. Phys. 2003, 118, $8207-8215$.

(31) Sathasivam, S.; Williamson, B. A. D.; Kafizas, A.; Althabaiti, S. A.; Obaid, A. Y.; Basahel, S. N.; Scanlon, D. O.; Carmalt, C. J.; Parkin, I. P. Computational and Experimental Study of $\mathrm{Ta}_{2} \mathrm{O}_{5}$ Thin Films. J. Phys. Chem. C 2017, 121, 202-210.

(32) Marchand, P.; Sathasivam, S.; Williamson, B. A. D.; Pugh, D.; Bawaked, S. M.; Basahel, S. N.; Obaid, A. Y.; Scanlon, D. O.; Parkin, I. P.; Carmalt, C. J. A Single-Source Precursor Approach to Solution Processed Indium Arsenide Thin Films. J. Mater. Chem. C 2016, 4, 6761.

(33) Williamson, B. A.; Buckeridge, J.; Brown, J.; Ansbro, S.; Palgrave, R. G.; Scanlon, D. O. Engineering Valence Band Dispersion for High Mobility P-Type Semiconductors. Chem. Mater. 2017, 29, $2402-2413$

(34) Oba, F.; Togo, A.; Tanaka, I.; Paier, J.; Kresse, G. Defect Energetics in ZnO: A Hybrid Hartree-Fock Density Functional Study. Phys. Rev. B: Condens. Matter Mater. Phys. 2008, 77, 245202.

(35) Chen, H.; Dawson, J. A. Nature of Nitrogen-Doped Anatase $\mathrm{TiO}_{2}$ and the Origin of Its Visible-Light Activity. J. Phys. Chem. C 2015, 119, 15890-15895.

(36) Kafizas, A.; Noor, N.; Carmichael, P.; Scanlon, D. O.; Carmalt, C. J.; Parkin, I. P. Combinatorial Atmospheric Pressure Chemical Vapor Deposition of $\mathrm{F}: \mathrm{TiO}_{2}$; The Relationship between Photocatalysis and Transparent Conducting Oxide Properties. Adv. Funct. Mater. 2014, 24, 1758-1771.

(37) Burbano, M.; Scanlon, D. O.; Watson, G. W. Sources of Conductivity and Doping Limits in CdO from Hybrid Density Functional Theory. J. Am. Chem. Soc. 2011, 133, 15065-15072.

(38) Rajpalke, M. K.; Linhart, W. M.; Birkett, M.; Yu, K. M.; Scanlon, D. O.; Buckeridge, J.; Jones, T. S.; Ashwin, M. J.; Veal, T. D. Growth and Properties of GaSbBi Alloys. Appl. Phys. Lett. 2013, 103, 142106.

(39) Ganose, A. M.; Savory, C. N.; Scanlon, D. O. $\left(\mathrm{CH}_{3} \mathrm{NH}_{3}\right)_{2} \mathrm{~Pb}-$ $(\mathrm{SCN})_{2} \mathrm{I}_{2}$ : A More Stable Structural Motif for Hybrid Halide Photovoltaics? J. Phys. Chem. Lett. 2015, 6, 4594-4598.

(40) Scanlon, D. O.; Walsh, A. Bandgap Engineering of $\mathrm{ZnSnP}_{2}$ for High-Efficiency Solar Cells. Appl. Phys. Lett. 2012, 100, 251911.

(41) Walsh, A.; Kehoe, A. B.; Temple, D. J.; Watson, G. W.; Scanlon, D. O. $\mathrm{PbO}_{2}$ : From Semi-Metal to Transparent Conducting Oxide by Defect Chemistry Control. Chem. Commun. (Cambridge, U. K.) 2013, 49, 448-450.

(42) Buckeridge, J.; Scanlon, D. O.; Walsh, A.; Catlow, C. R. A. Automated Procedure to Determine the Thermodynamic Stability of a Material and the Range of Chemical Potentials Necessary for Its Formation Relative to Competing Phases and Compounds. Comput. Phys. Commun. 2014, 185, 330-338.

(43) Çelik, V.; Mete, E. Range-Separated Hybrid ExchangeCorrelation Functional Analyses of Anatase $\mathrm{TiO}_{2}$ Doped with W, N, S, W/N, or W/S. Phys. Rev. B: Condens. Matter Mater. Phys. 2012, 86,205112

(44) Scanlon, D. O.; Dunnill, C. W.; Buckeridge, J.; Shevlin, S. A.; Logsdail, A. J.; Woodley, S. M.; Catlow, C. R. A.; Powell, M. J.; Palgrave, R. G.; Parkin, I. P.; Watson, G. W.; Keal, T. W.; Sherwood, P.; Walsh, A.; Sokol, A. A. Band Alignment of Rutile and Anatase $\mathrm{TiO}_{2}$. Nat. Mater. 2013, 12, 798-801.

(45) Huy, H. A.; Aradi, B.; Frauenheim, T.; Deák, P. Calculation of Carrier-Concentration-Dependent Effective Mass in Nb-Doped Anatase Crystals of $\mathrm{TiO}_{2}$. Phys. Rev. B: Condens. Matter Mater. Phys. 2011, 83, 155201.

(46) Janotti, A.; Varley, J. B.; Rinke, P.; Umezawa, N.; Kresse, G.; Van de Walle, C. G. Hybrid Functional Studies of the Oxygen Vacancy in $\mathrm{TiO}_{2}$. Phys. Rev. B: Condens. Matter Mater. Phys. 2010, 81, 85212 .

(47) Matsubara, M.; Saniz, R.; Partoens, B.; Lamoen, D. Doping Anatase $\mathrm{TiO}_{2}$ with Group V-B and VI-B Transition Metal Atoms: A Hybrid Functional First-Principles Study. Phys. Chem. Chem. Phys. 2017, 19, 1945-1952.

(48) Boonchun, A.; Reunchan, P.; Umezawa, N. Energetics of Native Defects in Anatase TiO 2: A Hybrid Density Functional Study. Phys. Chem. Chem. Phys. 2016, 18, 30040.

(49) Hine, N. D. M.; Frensch, K.; Foulkes, W. M. C.; Finnis, M. W. Supercell Size Scaling of Density Functional Theory Formation Energies of Charged Defects. Phys. Rev. B: Condens. Matter Mater. Phys. 2009, 79, 024112.

(50) Nieminen, R. M. Issues in First-Principles Calculations for Defects in Semiconductors and Oxides. Modell. Simul. Mater. Sci. Eng. 2009, 17, 084001.

(51) Murphy, S. T.; Hine, N. D. M. Anisotropic charge screening and supercell size convergence of defect formation energies. Phys. Rev. B: Condens. Matter Mater. Phys. 2013, 87, 094111. 
(52) Lany, S.; Zunger, A. Assessment of Correction Methods for the Band-Gap Problem and for Finite-Size Effects in Supercell Defect Calculations: Case Studies for $\mathrm{ZnO}$ and GaAs. Phys. Rev. B: Condens. Matter Mater. Phys. 2008, 78, 235104.

(53) Freysoldt, C.; Neugebauer, J.; Van De Walle, C. G. Fully Ab Initio Finite-Size Corrections for Charged-Defect Supercell Calculations. Phys. Rev. Lett. 2009, 102, 016402.

(54) Chase, J. M. NIST-JANAF Thermochemical Tables. J. Phys. Chem. Ref. Data Monogr. 1998, 9, 1.

(55) Artiglia, L.; Lazzari, D.; Agnoli, S.; Rizzi, G. A.; Granozzi, G. J. Phys. Chem. C 2013, 117, 13163-13172.

(56) Burdett, J. K.; Hughbanks, T.; Miller, G. J.; Richardson, J. W.; Smith, J. V. Structural-Electronic Relationships in Inorganic Solids: Powder Neutron Diffraction Studies of the Rutile and Anatase Polymorphs of Titanium Dioxide at 15 and 295 K. J. Am. Chem. Soc. 1987, 109, 3639-3646.

(57) Sabyrov, K.; Burrows, N. D.; Penn, R. L.; Merche, D.; Vandencasteele, N.; Reniers, F.; Yokoyama, T.; Kogoma, M.; Yokoyama, T.; Kogoma, M.; et al. Size-Dependent Anatase to Rutile Phase Transformation and Particle.pdf. Chem. Mater. 2013, 25, 14081415.

(58) Pore, V.; Ritala, M.; Leskelä, M.; Areva, S.; Järn, M.; Järnström, J. $\mathrm{H}_{2} \mathrm{~S}$ Modified Atomic Layer Deposition Process for Photocatalytic $\mathrm{TiO}_{2}$ Thin Films. J. Mater. Chem. 2007, 17, 1361.

(59) Kafizas, A.; Noor, N.; Carmalt, C. J.; Parkin, I. P. $\mathrm{TiO}_{2}$-Based Transparent Conducting Oxides; the Search for Optimum Electrical Conductivity Using a Combinatorial Approach. J. Mater. Chem. C 2013, 1, 6335.

(60) Sotelo-Vazquez, C.; Noor, N.; Kafizas, A.; Quesada-Cabrera, R.; Scanlon, D. O.; Taylor, A.; Durrant, J. R.; Parkin, I. P. Multifunctional P-Doped $\mathrm{TiO}_{2}$ Films: A New Approach to SelfCleaning, Transparent Conducting Oxide Materials. Chem. Mater. 2015, 27, 3234-3242.

(61) Evans, P.; Pemble, M. E.; Sheel, D. W. Precursor-Directed Control of Crystalline Type in Atmospheric Pressure CVD Growth of $\mathrm{TiO}_{2}$ on Stainless Steel. Chem. Mater. 2006, 18, 5750-5755.

(62) Buckeridge, J.; Butler, K. T.; Catlow, C. R. A.; Logsdail, A. J.; Scanlon, D. O.; Shevlin, S. A.; Woodley, S. M.; Sokol, A. A.; Walsh, A. Polymorph Engineering of $\mathrm{TiO}_{2}$ : Demonstrating How Absolute Reference Potentials Are Determined by Local Coordination. Chem. Mater. 2015, 27, 3844-3851.

(63) Landmann, M.; Rauls, E.; Schmidt, W. G. The Electronic Structure and Optical Response of Rutile, Anatase and Brookite $\mathrm{TiO}_{2}$. J. Phys.: Condens. Matter 2012, 24, 195503.

(64) Dou, M.; Persson, C. Comparative Study of Rutile and Anatase $\mathrm{SnO}_{2}$ and $\mathrm{TiO}_{2}$ : Band-Edge Structures, Dielectric Functions, and Polaron Effects. J. Appl. Phys. 2013, 113, 083703.

(65) Tang, H.; Lévy, F.; Berger, H.; Schmid, P. E. Urbach Tail of Anatase $\mathrm{TiO}_{2}$. Phys. Rev. B: Condens. Matter Mater. Phys. 1995, 52, $7771-7774$.

(66) Patrick, C. E.; Giustino, F. GW Quasiparticle Bandgaps of Anatase $\mathrm{TiO}_{2}$ Starting from DFT + U. J. Phys.: Condens. Matter 2012, 24, 202201.

(67) Kang, W.; Hybertsen, M. S. Quasiparticle and Optical Properties of Rutile and Anatase $\mathrm{TiO}_{2}$. Phys. Rev. B: Condens. Matter Mater. Phys. 2010, 82, 085203.

(68) Gong, S.; Liu, B.-G. Electronic Structures and Optical Properties of $\mathrm{TiO}_{2}$ : Improved Density-Functional-Theory Investigation. Chin. Phys. B 2012, 21, 057104.

(69) Chiodo, L.; Salazar, M.; Romero, A. H.; Laricchia, S.; Della Sala, F.; Rubio, A. Structure, Electronic, and Optical Properties of $\mathrm{TiO}_{2}$ Atomic Clusters: An Ab Initio Study. J. Chem. Phys. 2011, 135, 244704.

(70) Morgan, B. J.; Watson, G. W. Intrinsic N-Type Defect Formation in $\mathrm{TiO}_{2}$ : A Comparison of Rutile and Anatase from GGA +U Calculations. J. Phys. Chem. C 2010, 114, 2321-2328.

(71) Mattioli, G.; Alippi, P.; Filippone, F.; Caminiti, R.; Amore Bonapasta, A. Deep versus Shallow Behavior of Intrinsic Defects in
Rutile and Anatase $\mathrm{TiO}_{2}$ Polymorphs. J. Phys. Chem. C 2010, 114, 21694-21704.

(72) Deák, P.; Aradi, B.; Frauenheim, T. Polaronic Effects in $\mathrm{TiO}_{2}$ Calculated by the HSE06 Hybrid Functional: Dopant Passivation by Carrier Self-Trapping. Phys. Rev. B: Condens. Matter Mater. Phys. 2011, 83, 155207.

(73) Morgan, B. J.; Watson, G. W. Polaronic Trapping of Electrons and Holes by Native Defects in Anatase $\mathrm{TiO}_{2}$. Phys. Rev. B: Condens. Matter Mater. Phys. 2009, 80, 233102.

(74) Oba, F.; Nishitani, S. R.; Isotani, S.; Adachi, H.; Tanaka, I. Energetics of Native Defects in ZnO. J. Appl. Phys. 2001, 90, 824828.

(75) Janotti, A.; Van De Walle, C. G. Native Point Defects in ZnO. Phys. Rev. B: Condens. Matter Mater. Phys. 2007, 76, 165202.

(76) Agoston, P.; Albe, K.; Nieminen, R. M.; Puska, M. J. Intrinsic N-Type Behavior in Transparent Conducting Oxides: A Comparative Hybrid-Functional Study of $\mathrm{In}_{2} \mathrm{O}_{3}, \mathrm{SnO}_{2}$, and $\mathrm{ZnO}$. Phys. Rev. Lett. 2009, 103, 245501.

(77) Scanlon, D. O.; Watson, G. W. On the Possibility of P-Type $\mathrm{SnO}_{2}$. J. Mater. Chem. 2012, 22, 25236-25245.

(78) Kílíç, C.; Zunger, A. Origins of Coexistence of Conductivity and Transparency in $\mathrm{SnO}_{2}$. Phys. Rev. Lett. 2002, 88, 95501.

(79) Singh, A. K.; Janotti, A.; Scheffler, M.; Van De Walle, C. G. Sources of Electrical Conductivity in $\mathrm{SnO}_{2}$. Phys. Rev. Lett. 2008, 101, 055502 .

(80) Walsh, A.; Catlow, C. R. A.; Sokol, A. A.; Woodley, S. M. Physical Properties, Intrinsic Defects, and Phase Stability of Indium Sesquioxide. Chem. Mater. 2009, 21, 4962-4969.

(81) Ágoston, P.; Albe, K. Formation Entropies of Intrinsic Point Defects in Cubic $\mathrm{In}_{2} \mathrm{O}_{3}$ from First-Principles Density Functional Theory Calculations. Phys. Chem. Chem. Phys. 2009, 11, 3226.

(82) Lany, S.; Zunger, A. Polaronic Hole Localization and Multiple Hole Binding of Acceptors in Oxide Wide-Gap Semiconductors. Phys. Rev. B: Condens. Matter Mater. Phys. 2009, 80, 085202.

(83) Goyal, A.; Gorai, P.; Peng, H.; Lany, S.; Stevanović, V. A Computational Framework for Automation of Point Defect Calculations. Comput. Mater. Sci. 2017, 130, 1-9.

(84) Scanlon, D. O. Defect Engineering of $\mathrm{BaSnO}_{3}$ for HighPerformance Transparent Conducting Oxide Applications. Phys. Rev. B: Condens. Matter Mater. Phys. 2013, 87, 161201.

(85) Deák, P.; Aradi, B.; Frauenheim, T. Quantitative Theory of the Oxygen Vacancy and Carrier Self-Trapping in Bulk $\mathrm{TiO}_{2}$. Phys. Rev. B: Condens. Matter Mater. Phys. 2012, 86, 195206.

(86) Deák, P.; Aradi, B.; Frauenheim, T. Oxygen Deficiency in $\mathrm{TiO}_{2}$ : Similarities and Differences between the Ti Self-Interstitial and the O Vacancy in Bulk Rutile and Anatase. Phys. Rev. B: Condens. Matter Mater. Phys. 2015, 92, 045204.

(87) Na-Phattalung, S.; Smith, M. F.; Kim, K.; Du, M. H.; Wei, S. H.; Zhang, S. B.; Limpijumnong, S. First-Principles Study of Native Defects in Anatase $\mathrm{TiO}_{2}$. Phys. Rev. B: Condens. Matter Mater. Phys. 2006, 73, 125205.

(88) Dixon, S. C.; Sathasivam, S.; Williamson, B. A. D.; Scanlon, D. O.; Carmalt, C. J.; Parkin, I. P. Transparent Conducting N-Type $\mathrm{ZnO}:$ Sc-Synthesis, Optoelectronic Properties and Theoretical Insight. J. Mater. Chem. C 2017, 5, 7585.

(89) Zhao, W.; Ma, W.; Chen, C.; Zhao, J.; Shuai, Z. Efficient Degradation of Toxic Organic Pollutants with $\mathrm{Ni}_{2} \mathrm{O}_{3} / \mathrm{TiO}_{2}-\mathrm{XBX}$ under Visible Irradiation. J. Am. Chem. Soc. 2004, 126, 4782-4783.

(90) Yang, K.; Dai, Y.; Huang, B. Origin of the Photoactivity in Boron-Doped Anatase and Rutile $\mathrm{TiO}_{2}$ Calculated from First Principles. Phys. Rev. B: Condens. Matter Mater. Phys. 2007, 76, 195201.

(91) Gombac, V.; De Rogatis, L.; Gasparotto, A.; Vicario, G.; Montini, T.; Barreca, D.; Balducci, G.; Fornasiero, P.; Tondello, E.; Graziani, $\mathrm{M}$. $\mathrm{TiO}_{2}$ Nanopowders Doped with Boron and Nitrogen for Photocatalytic Applications. Chem. Phys. 2007, 339, 111-123.

(92) Geng, H.; Yin, S.; Yang, X.; Shuai, Z.; Liu, B. Geometric and Electronic Structures of the Boron-Doped Photocatalyst $\mathrm{TiO}_{2}$. J. Phys.: Condens. Matter 2006, 18, 87-96. 
(93) Li, L.; Meng, F.; Hu, X.; Qiao, L.; Sun, C. Q.; Tian, H.; Zheng, W. $\mathrm{TiO}_{2}$ Band Restructuring by B and P Dopants. PLoS One 2016, 11, e0152726. 